\title{
Crustal deformations associated with the great Sumatra-Andaman earthquake deduced from continuous GPS observation
}

\author{
Manabu Hashimoto ${ }^{1}$, Nithiwatthn Choosakul ${ }^{2}$, Michio Hashizume $^{2}$, Shuzo Takemoto ${ }^{3}$, Hiroshi Takiguchi ${ }^{3}$, \\ Yoichi Fukuda ${ }^{3}$, and Kunio Fujimori ${ }^{3}$ \\ ${ }^{1}$ DPRI, Kyoto University, Gokasho, Uji, Kyoto 611-0011, Japan \\ ${ }^{2}$ Department of Geology, Chulalongkorn University, Phayathai Road, Bangkok 10330, Thailand \\ ${ }^{3}$ Geophysical Institute, Kyoto University, Kitashirakara-Oiwakecho, Sakyo-ku, Kyoto 606-8502, Japan
}

(Received July 20, 2005; Revised February 9, 2006; Accepted February 9, 2006; Online published February 17, 2006)

\begin{abstract}
We analyzed continuous GPS data from more than 20 sites in Asia, Australia and islands in Indian Ocean in order to detect crustal deformations associated with the Sumatra-Andaman earthquake of December 26, 2004. Coseismic steps can be recognized at sites about 3,000 km away from the epicenter such as Kunming in south China, Quezon in Philippines, and Diego Garcia Island in central Indian Ocean. The largest displacement of about $26 \mathrm{~cm}$ is found at Phuket in Thailand about $600 \mathrm{~km}$ away from the epicenter, about twice as large as that at Sampari, the nearest site in northern Sumatra. These observations suggest that as large slip as $14 \mathrm{~m}$ occurred beneath the Nicobar Islands. Large postseismic displacements are observed at Phuket and Sampari after the mainshock, but the former is three times larger than the latter. This suggests that the spatial distribution of afterslip is different from the coseismic slip distribution. The temporal variation of postseismic displacements can be explained by a logarithmic function derived from rate-state dependent friction law with short characteristic time. The area where coseismic displacements from the Nias earthquake of March 28, 2005 are detected is much smaller than that from the December mainshock, but displacement at Sampari is larger than that during the mainshock. These displacements suggest less than $4 \mathrm{~m}$ slip on a shallow dipping thrust fault and resultant moment release is smaller than that estimated from seismological data. Finally, total moment released by afterslip amounts to $3.83 \times 10^{22} \mathrm{Nm}$ which is equivalent to $\mathrm{Mw} 8.99$ for about five months, including the afterslip for the Nias earthquake.
\end{abstract}

Key words: Sumatra-Andaman earthquake, Nias earthquake, coseismic deformation, postseismic deformation, GPS, fault model.

\section{Introduction}

The Great Sumatra-Andaman earthquake of December 26, 2004 was the first event of Mw 9 or larger since the global continuous monitoring network of GPS started its operation. Thanks to its high accuracy, we can expect that coseismic displacements can be observed several hundreds or more $\mathrm{km}$ away from the epicenter. The rupture process of the December 26, 2004 Sumatra-Andaman earthquake has been proposed to include a large slow-slip component (e.g. Bilham, 2005). Coseismic static displacements pose upper bound on the size of rupture and the difference from that estimated from seismic waves must have been caused by slow rupture that cannot be detected by ordinal seismographs. Continuous GPS can give the best estimate of coseismic displacements. Therefore geodesists tried to collect all the available data and derive coseismic displacements (e.g. Banerjee et al., 2005; Vigny et al., 2005; Earnest and Rajendran, 2005). On March 28, 2005, another large event with $\mathrm{Mw}>8$, Nias earthquake, occurred in southern neighbor of the source region of the Sumatra-Andaman earthquake. It is interesting to understand how the mainshock

Copyright (c) The Society of Geomagnetism and Earth, Planetary and Space Sciences (SGEPSS); The Seismological Society of Japan; The Volcanological Society of Japan; The Geodetic Society of Japan; The Japanese Society for Planetary Sciences; TERRAPUB affected the Nias event from the viewpoint of stress interaction between earthquakes. We need a fault model for this earthquake before discussing the stress interaction. GPS also provides useful dataset for the analysis of this earthquake.

Large interplate earthquakes are usually accompanied by postseismic deformations that last for a year or more. Large postseismic deformations followed the 1994 Sanriku earthquake (Heki et al., 1997). The equivalent magnitude of postseismic deformation exceeded 7. The 2003 TokachiOki earthquake is also accompanied by postseismic deformations, which might have loaded the segments around the source region of the mainshock (Murakami, 2005; Miura et al., 2005). 14 months later, the segment of its eastern neighbor broke to cause a $\mathrm{Mw} 7$ earthquake, which implies afterslip may play an important role in stress transfer. The 1964 Alaska and 1960 Chilean earthquakes are also examples that were followed by long lasting postseismic deformations (Wang et al., 2002; Larsen et al., 2003). Long-lasting postseismic deformations are expected for the Sumatra-Andaman earthquake considering its size. Thus it is extremely important to watch its variation in space and time, because it will convey information on anelastic structure of the earth's mantle, frictional property of the plate interface etc. Therefore we collect continuous GPS data as 

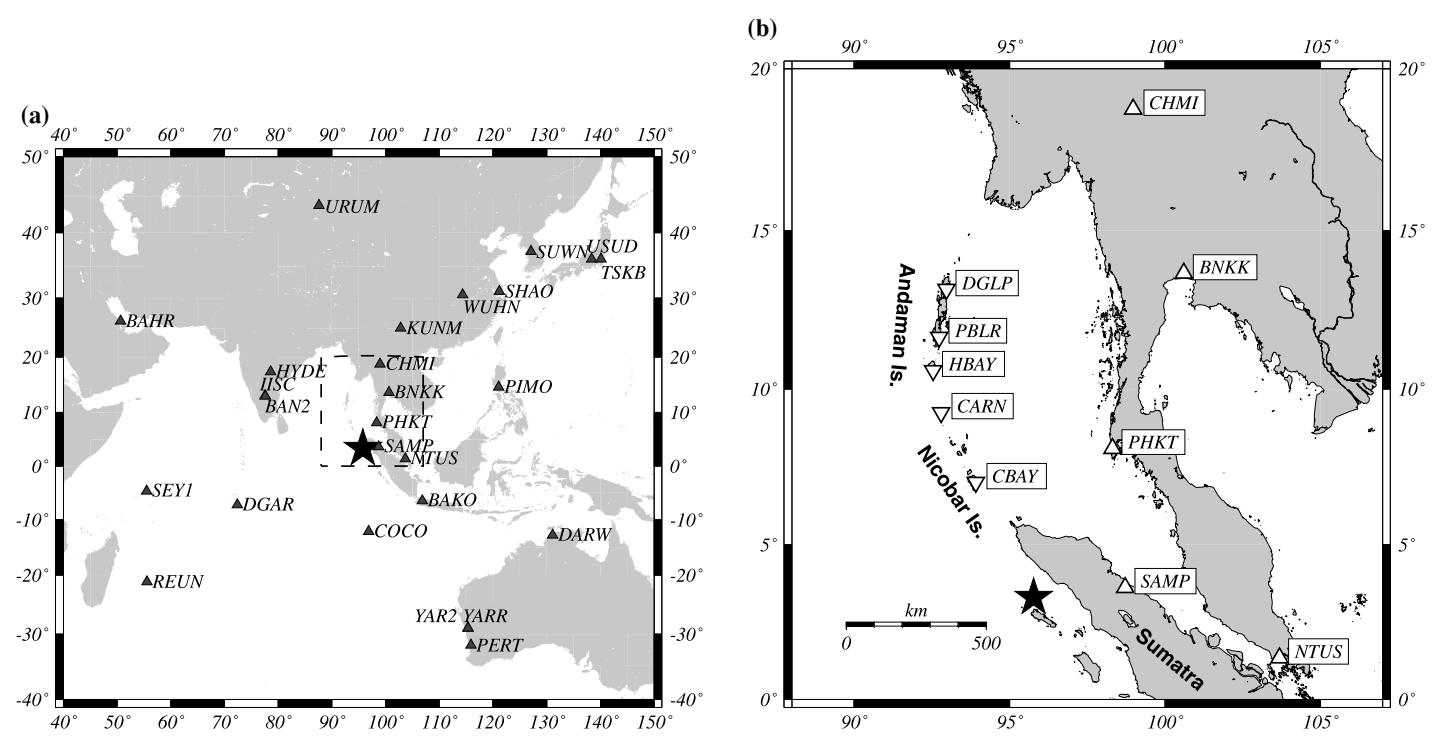

Fig. 1. (a) Distribution of continuous GPS sites used in this study. A black star indicates the epicenter of the December 26 Sumatra-Andaman earthquake. Dashed rectangle shows the region shown in Fig. 1(b). (b) Close up of the region in the rectangle in Fig. 1(a). Inverted open triangles show campaign GPS sites in Andama-Nicobar Islands, whose data were reported in Earnest and Rajendran (2005).

Table 1. Position and availability of continuous GPS sites used in this study.

\begin{tabular}{|c|c|c|c|c|c|c|c|}
\hline Code & Name & Lon & Lat & $\Delta$ & Affiliation & Plate & Period (yr.doy-yr.doy) \\
\hline BAHR & Bahrain & 50.61 & 26.21 & 5442 & IGS & ARAB & $04.340-05.135$ \\
\hline BAKO & Cibinong & 106.85 & -6.49 & 1639 & IGS & EURA & $04.340-05.135$ \\
\hline BAN2 & Bangalore & 77.51 & 13.03 & 2280 & IGS & INDI & $04.340-05.135$ \\
\hline BNNK & Bangkok & 100.61 & 13.67 & 1264 & $\mathrm{CU}$ & EURA & $04.340-05.135$ \\
\hline CHMI & Changmai & 98.97 & 18.77 & 1746 & $\mathrm{CU}$ & EURA & $04.340-05.090$ \\
\hline $\mathrm{COCO}$ & Cocos Island & 96.83 & -12.19 & 1717 & IGS & AUST & $04.340-05.135$ \\
\hline DARW & Darwin & 131.13 & -12.84 & 4296 & IGS & AUST & $04.340-05.135$ \\
\hline DGAR & Diego Garcia & 72.37 & -7.27 & 2851 & IGS & INDI & $04.340-05.135$ \\
\hline HYDE & Hyderabad & 78.55 & 17.42 & 2445 & IGS & INDI & $04.340-05.135$ \\
\hline IISC & Bangalore & 77.57 & 13.02 & 2274 & IGS & INDI & $04.340-05.135$ \\
\hline KUNM & Kunming & 102.80 & 25.03 & 2519 & IGS & EURA & $04.340-05.135$ \\
\hline LHAS & Lhasa & 91.10 & 29.66 & 2959 & IGS & EURA & $04.340-05.135$ \\
\hline NTUS & Singapore & 103.68 & 1.35 & 905 & IGS & EURA & $04.340-05.135$ \\
\hline PERT & Perth & 115.89 & -31.80 & 4429 & IGS & AUST & $04.340-05.069$ \\
\hline PHKT & Phuket & 98.31 & 8.10 & 600 & $\mathrm{CU}$ & EURA & $04.340-05.135$ \\
\hline PIMO & Quezon & 121.08 & 14.64 & 3047 & IGS & EURA & $04.340-05.087$ \\
\hline REUN & Reunion & 55.57 & -21.21 & 5154 & IGS & AFRC & $04.340-05.135$ \\
\hline SAMP & Sampari & 98.71 & 3.62 & 327 & BAKO & EURA & $04.340-05.135$ \\
\hline SEY1 & Seyshel & 55.48 & -4.67 & 4568 & IGS & AFRC & $04.340-05.059$ \\
\hline SHAO & Shanghai & 121.20 & 31.10 & 4072 & IGS & EURA & $04.340-05.135$ \\
\hline SUWN & Suwon & 127.05 & 37.28 & 4934 & IGS & EURA & $04.340-05.135$ \\
\hline TSKB & Tsukuba & 140.09 & 36.11 & 5815 & IGS & EURA & $04.340-05.135$ \\
\hline URUM & Urumqi & 87.60 & 43.81 & 4560 & IGS & EURA & $04.340-05.074$ \\
\hline USUD & Usuda & 138.36 & 36.13 & 5680 & IGS & EURA & $04.340-05.135$ \\
\hline WUHN & Wuhan & 114.36 & 30.53 & 3592 & IGS & EURA & $04.340-05.135$ \\
\hline YAR2 & Yarragadee & 115.35 & -29.05 & 4145 & IGS & AUST & $04.340-05.135$ \\
\hline YARR & Yarragadee & 115.35 & -29.05 & 4145 & IGS & AUST & $04.340-05.135$ \\
\hline
\end{tabular}

$\Delta$ is distance from the epicenter of the December mainshock ( ) in $\mathrm{km}$. Abbreviations for affiliations are as follows: IGS, International GPS Service; CU, Chulalongkorn University; BAKO, BAKOSURUTANAL. "Plate" indicates the assigned plate adopted in Bernese 5.0. Abbreviations are as follows: AFRC, African; ARAB, Arabian; EURA, Eurasia; AUST, Australia; INDI, Indian plates.

much as possible and analyze them in order to clarify the crustal deformations associated with this historic event.

\section{GPS Data}

We collected daily RINEX files of 22 IGS sites and 4 local continuous observation sites operated by BAKO-
SURUTANAL of Indonesia and the Chulalongkorn University, Thailand (Fig. 1, Table 1). Data of IGS and Indonesian sites were obtained from the SOPAC website (http://garner.ucsd.edu) or the ftp site of the Geographical Survey Institute, Japan. Three continuous sites in Thailand (Phuket (PHKT), Bangkok (BNKK), and Chiangmai 


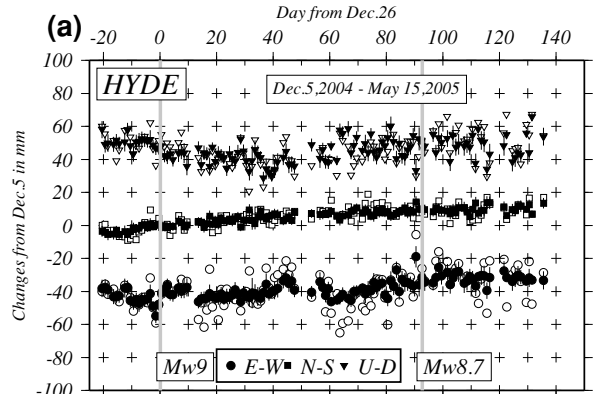

(b)

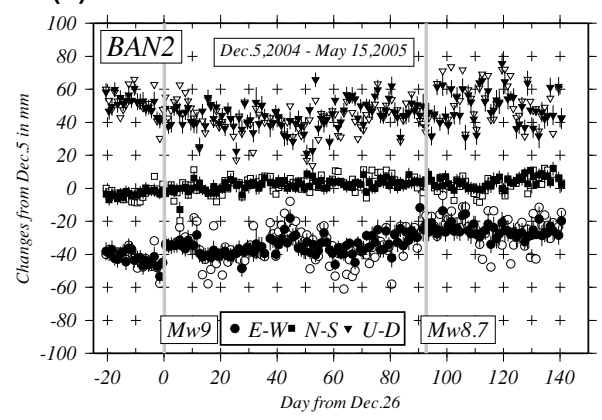

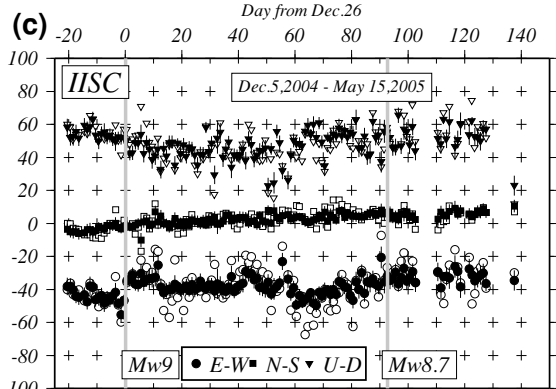

(d)

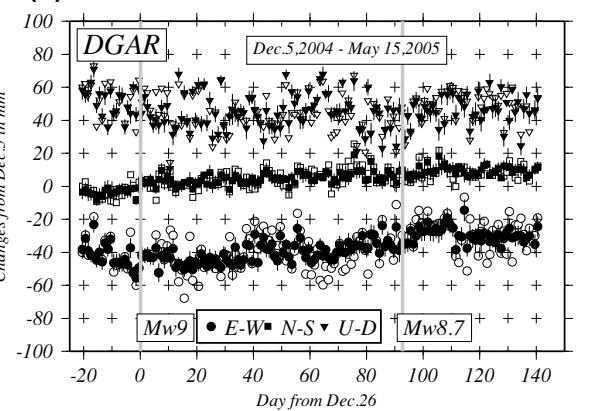

Fig. 2. Time series of coordinate changes in mm at continuous GPS sites since December 5, 2004. Abscissas are elapsed time in days since the December 26 Sumatra-Andaman earthquake. Thick vertical lines indicate the occurrence of the December mainshock and March 28 , 2005, Nias earthquake. Open and solid symbols indicate raw and spatial-filtered components of coordinate, respectively. Circles, squares, and inverted triangles show eastward, northward and vertical components, respectively. (a) Hyderabad, (b) Bangalore, (c) Bangalore, (d) Diego Garcia, (e) Wuhan, (f) Kunming, (g) Lhasa, (h) Chiangmai, (i) Cocos Island, (j) Singapore, (k) Cibinong, (l) Manila, (m) Bangkok, (n) Phuket, and (o) Sampari.

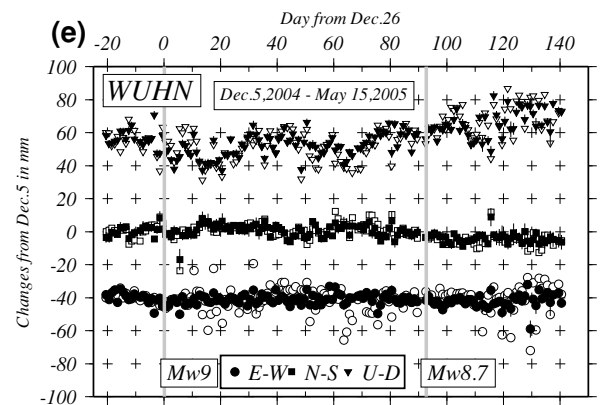$$
\text { (f) }
$$

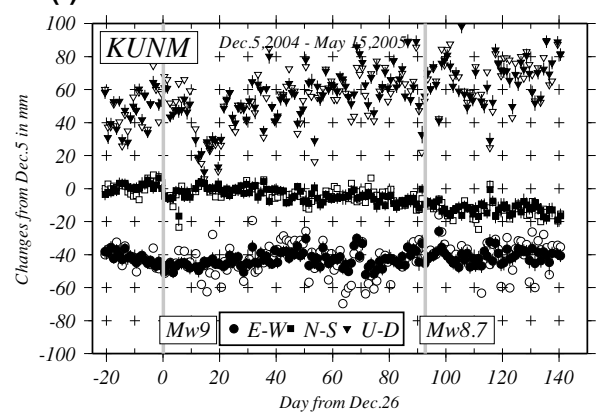

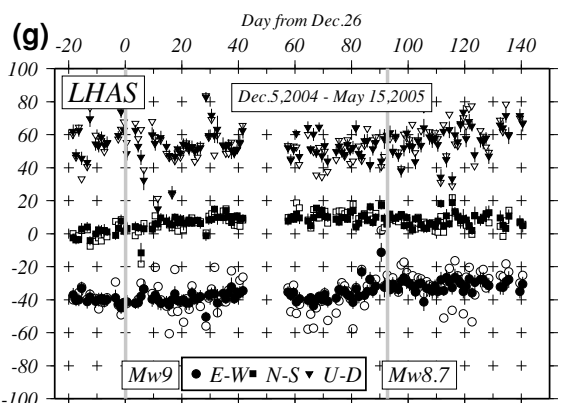

(h)

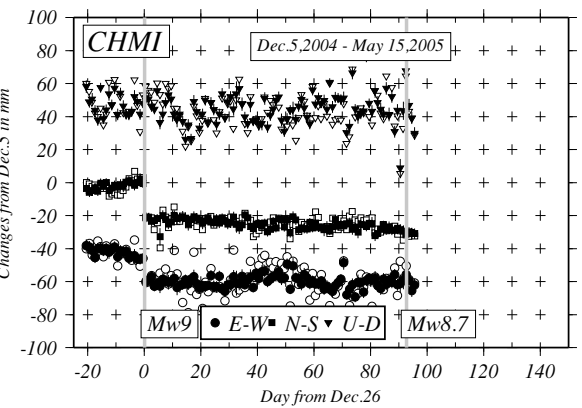

Fig. 2. (continued).

(CHMI)) were originally established under joint prgram between FRONTIER and the Chulalongkorn University. The closest site is Sampari (SAMP) in northern Sumatra, whose epicentral distance is $\sim 327 \mathrm{~km}$, while the farthest is Tsukuba (TSKB) in Japan which is located about 5,800 km away from the epicenter.

We collected data since December 5 (DOY 340) in order to obtain stable estimates of average coordinates before December 26 (DOY 361). So far we analyzed data till May
15, 2005 (DOY 135). Availability of data is listed in Table 1 . There are still missing data because of instrument trouble, replacement, delayed logging and other unknown reasons. On average, coordinates of more than 20 sites are determined for half a year daily.

Dual frequency receivers such as Trimble 4000 series, Ashtech Z12 or their equivalents are operated at all sites. Most sites are equipped with choke-ring antenna with radome. Sampling interval is usually $30 \mathrm{sec}$. At some sites 

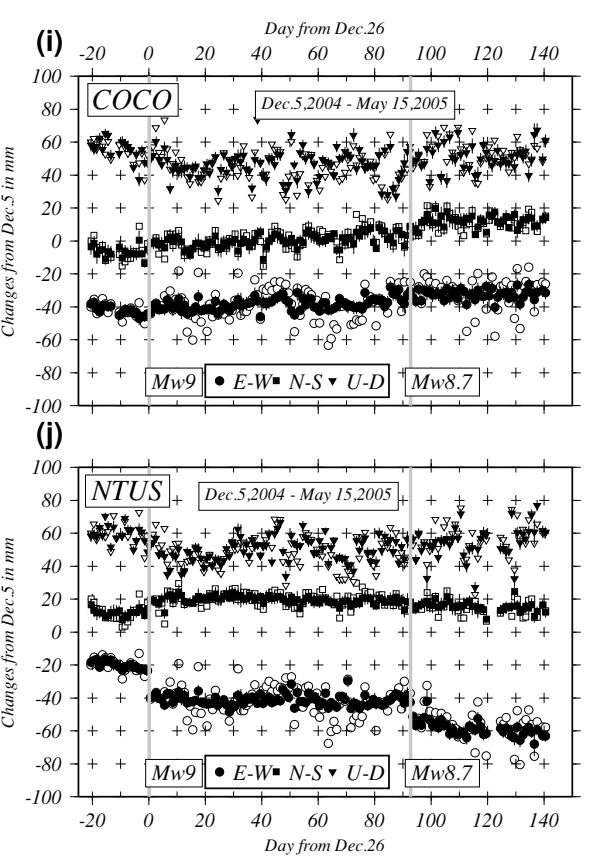

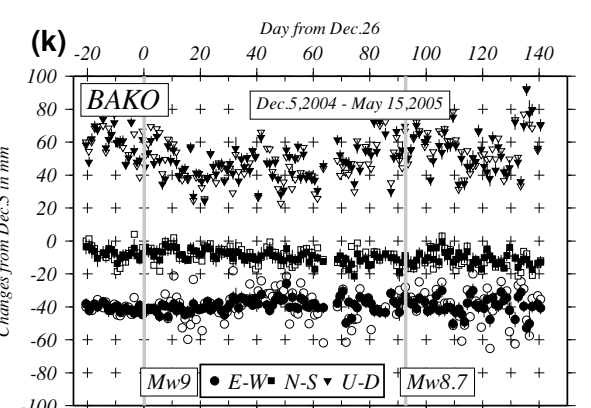

(I)

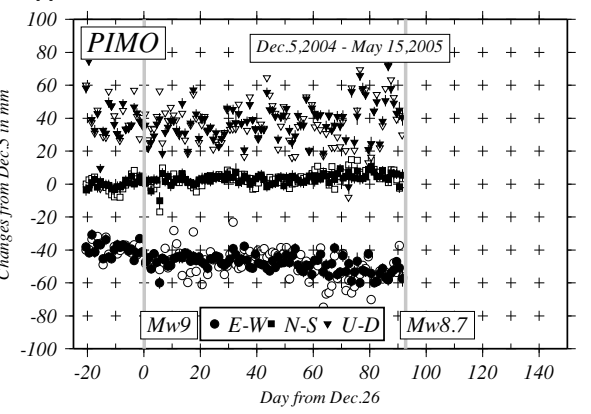

Fig. 2. (continued).
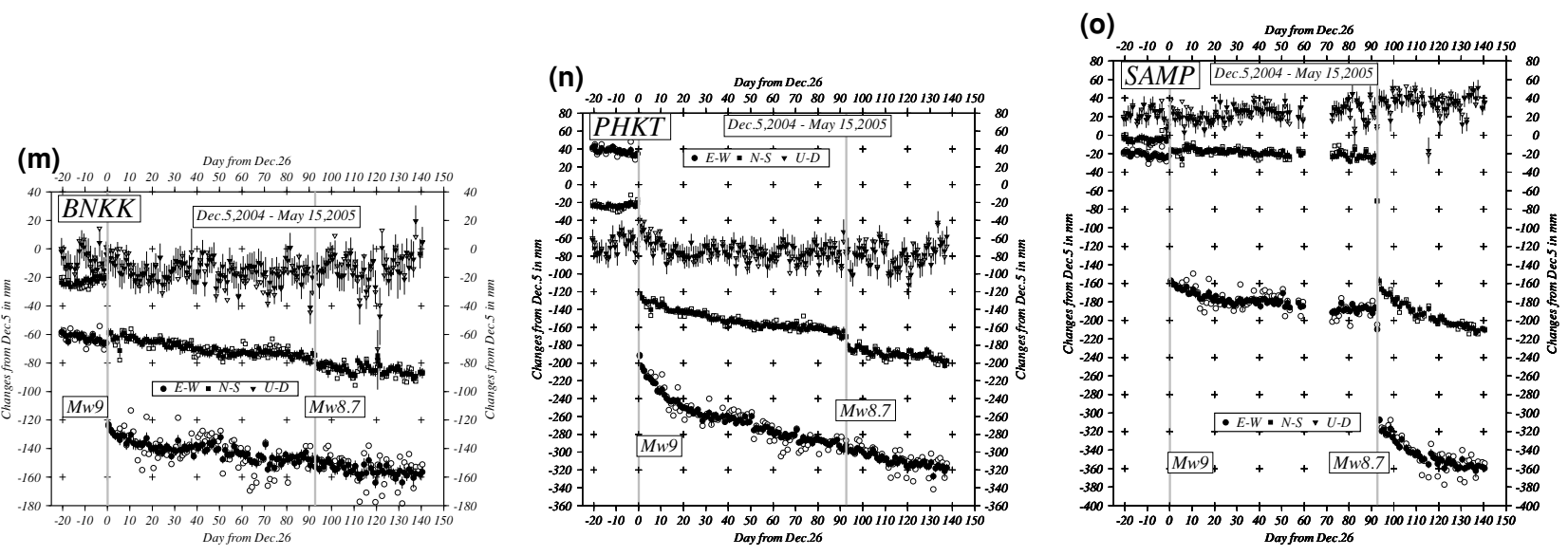

Fig. 2. (continued).

such as Perth (PERT), they are observing at much higher rate. In such case we use RINEX files decimated to $30 \mathrm{sec}$.

\section{Analysis}

We use Bernese 5.0 software with Bernese Process Engine for the static positioning of daily coordinates (Hugentobler et al., 2005). IGS final ephemeredes, earth rotation parameters and satellite clock coefficients are used. We obtain differential code biases (DCB) for satellites and receivers and ionosphere model parameters that are necessary for Bernese 5.0 from the ftp site of AIUB of the University of Bern. Ocean tide model coefficients are calculated based on GOT00.2 at the website of the Onsala Space Observatory. According to the default of the Benrnese Process Engine, we use an elevation mask of $10 \mathrm{deg}$. Raw phase data are smoothed before the analysis using the module named RNXSMT. Using smoothed data we first estimate a priori position everyday with Besrnese's precise point positioning scheme. The final coordinates are calcu- lated using this a priori position. Tropospheric zenith delays are estimated every hour introducing their horizontal gradients. Integer biases are fixed with Quasi-Ionospheric Free (QIF) Strategy even for longer baselines than 2,000 km since the island sites such as Diego Garcia Island (DGAR) in Indian Ocean are located 2,000 km away from the nearest site. In order to align the site coordinates in the ITRF2000, we tried to strongly constrain remote sites such as TSKB, Urumqi (URUM), Bahrain (BAHR) and others to their predicted coordinates in ITRF2000. However their preliminarily estimated coordinate sometimes largely differ from the ITRF2000 predictions. In such a case, we did not constrain their coordinates.

Time series of coordinates of representative sites are shown as open symbols in Fig. 2. Abscissa is day from December 26 (DOY 361), 2004. There is a relatively large scatter especially in EW components. We suspect that these scatters may be a common noise that can be attributed to unknown systematic error in ephemeredes or common 


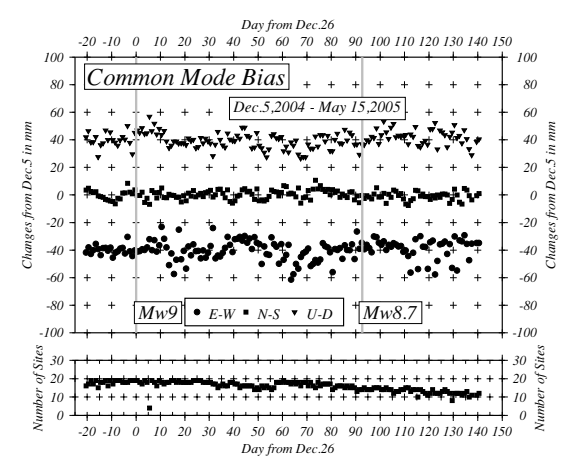

Fig. 3. Common mode bias estimated from the coordinate changes in the present network excluding sites affected by co- and postseismic deformations with the number of sites used in the daily calculation.

data. Thus we apply the spatial filter technique proposed by Wdowinski et al. (1997) and Tabei and Amin (2002). We excluded the sites that may have suffered from coseismic and postseismic deformations from the calculation of common mode bias such as SAMP, PHKT, BNKK, Singapore (NTUS), Cocos Island (COCO) etc. We divided the entire period into two at the occurrence of December mainshock and calculated the linear trends for each period separately. If we separate the period on the occurrence of the Nias earthquake, we found large movements before and after the Nias earthquake at far sites such as TSKB and SUWN. Considering the epicentral distance and the magnitude, we regard these movements as artificial ones and did not separate the period for calculation trend on March 28, 2005. Figure 3 shows time series of estimated common mode bias with the number of sites used for the calculation. A large scatter with peak-to-peak amplitude of $30 \mathrm{~mm}$ is recognized in the EW component. Therefore we exclude this common mode bias from the raw coordinate changes. We discuss crustal deformation based on these filtered time series. Finally we eliminate steady plate motion with relative to the Sunda shelf block using Bock et al.'s (2003) rotation pole and calculate coseismic/postseismic horizontal displacements.

\section{Time Series of Coordinates}

Figure 2 also shows filtered time series of coordinate changes. Large steps are observed at PHKT, SAMP, BNKK and $\mathrm{CHMI}$ at day 0 , which indicates coseismic steps from the mainshock. We take averages of coordinates during 5 days before the mainshock and subtract those from the coordinates on December 27 to calculate coseismic displacements, since there are fluctuations in time series data. Thus estimated displacements are listed in Table 2. The amount of coseismic step of $239.2 \pm 2.3 \mathrm{~mm}$ to the west and $104.4 \pm 2.0 \mathrm{~mm}$ to the south at PHKT is the largest. SAMP also has a large coseismic step of $137.3 \pm 1.5 \mathrm{~mm}$ to the west and $12.5 \pm 2.1 \mathrm{~mm}$ to the south. BNKK has a displacement of $61.9 \pm 1.5 \mathrm{~mm}$ to the west and $37.7 \pm 1.5 \mathrm{~mm}$ to the south, while CHMI shifts by $13.9 \pm 1.3 \mathrm{~mm}$ to the west and $20.8 \pm 1.5 \mathrm{~mm}$ to the south. We also recognize small steps at sites more than 1,000 km away from the epicenter. Indian sites such as Bangalore (BAN2, IISC) and Hyderabad (HYDE) moved eastward by about $10 \mathrm{~mm}$. Kunming (KUNM) in south China was displaced southward by $\sim 8$
Table 2. Estimated coseismic displacements at continuous GPS sites from the December 26 Sumatra-Andaman earthquake.

\begin{tabular}{|c|c|c|c|}
\hline Site & $\mathrm{dE}(\mathrm{mm})$ & $\mathrm{dN}(\mathrm{mm})$ & $\mathrm{dU}(\mathrm{mm})$ \\
\hline BAHR & $0.5 \pm 4.7$ & $1.7 \pm 2.1$ & $4.6 \pm 4.6$ \\
\hline BAKO & $1.0 \pm 2.2$ & $2.7 \pm 2.4$ & $-3.7 \pm 9.5$ \\
\hline BAN2 & $11.6 \pm 3.8$ & $0.4 \pm 1.4$ & $-7.6 \pm 5.1$ \\
\hline BNKK & $-61.9 \pm 1.5$ & $-37.7 \pm 1.5$ & $1.9 \pm 7.7$ \\
\hline CHMI & $-13.9 \pm 1.3$ & $-20.8 \pm 1.5$ & $4.0 \pm 5.1$ \\
\hline $\mathrm{COCO}$ & $5.8 \pm 1.6$ & $7.1 \pm 4.1$ & $3.6 \pm 6.4$ \\
\hline DARW & $0.0 \pm 3.0$ & $5.5 \pm 4.3$ & $2.2 \pm 8.9$ \\
\hline DGAR & $7.5 \pm 4.9$ & $6.0 \pm 3.3$ & $2.5 \pm 7.6$ \\
\hline HYDE & $9.0 \pm 4.0$ & $-0.1 \pm 1.3$ & $-6.7 \pm 3.0$ \\
\hline IISC & $13.4 \pm 4.3$ & $0.1 \pm 1.4$ & $-9.0 \pm 2.4$ \\
\hline KUNM & $-1.2 \pm 1.8$ & $-7.5 \pm 2.3$ & $4.7 \pm 7.5$ \\
\hline NTUS & $-16.7 \pm 1.3$ & $6.8 \pm 2.0$ & $-2.0 \pm 5.2$ \\
\hline PERT & $3.1 \pm 2.3$ & $8.0 \pm 6.0$ & $-6.7 \pm 9.3$ \\
\hline PHKT & $-239.2 \pm 2.3$ & $-104.4 \pm 2.0$ & $12.5 \pm 7.3$ \\
\hline PIMO & $-4.6 \pm 4.5$ & $0.3 \pm 2.1$ & $-17.9 \pm 5.9$ \\
\hline REUN & $4.5 \pm 8.2$ & $5.7 \pm 3.1$ & $12.8 \pm 12.3$ \\
\hline SAMP & $-137.3 \pm 1.5$ & $-12.5 \pm 2.1$ & $6.2 \pm 8.5$ \\
\hline SEY1 & $0.0 \pm 5.8$ & $2.4 \pm 2.5$ & $-5.9 \pm 11.8$ \\
\hline SHAO & $-3.6 \pm 3.2$ & $-2.2 \pm 4.1$ & $-3.0 \pm 5.7$ \\
\hline SUWN & $-4.0 \pm 4.7$ & $0.8 \pm 5.7$ & $-11.5 \pm 9.3$ \\
\hline TSKB & $-5.1 \pm 7.3$ & $2.1 \pm 5.2$ & $-3.0 \pm 8.3$ \\
\hline URUM & $2.0 \pm 3.5$ & $-4.9 \pm 4.0$ & $-5.9 \pm 4.2$ \\
\hline USUD & $-3.7 \pm 7.5$ & $1.9 \pm 5.3$ & $-2.0 \pm 6.7$ \\
\hline WUHN & $-1.6 \pm 3.6$ & $-2.5 \pm 3.8$ & $-5.7 \pm 8.3$ \\
\hline YAR2 & $4.2 \pm 2.2$ & $7.7 \pm 5.6$ & $-1.0 \pm 7.5$ \\
\hline YARR & $4.0 \pm 2.5$ & $7.2 \pm 5.6$ & $-3.2 \pm 8.7$ \\
\hline BAHR & $0.5 \pm 4.7$ & $1.7 \pm 2.1$ & $4.6 \pm 4.6$ \\
\hline
\end{tabular}

$\mathrm{mm}$. The farthest site at which the coseismic step is recognized is Quezon (PIMO) in Philippines, whose coseismic shift is $4.6 \pm 4.5 \mathrm{~mm}$ to the west and $0.3 \pm 2.1 \mathrm{~mm}$ to the north. Its epicentral distance is about $3,000 \mathrm{~km}$. No significant displacements are recognized at farther sites. It is important to note that Cibinong (BAKO) in western Java and Lhasa (LHAS) in Tibet have no significant coseismic displacements despite of its shorter epicentral distance than that of PIMO. It is easy to understand that both sites are located on the nodal line of displacement field. PHKT might have uplifted by $12.5 \pm 7.3 \mathrm{~mm}$, but we would like to reserve the conclusion whether PHKT was uplifted, since large disturbances appeared before and after the mainshock.

Decaying motions following the coseismic steps are observed at PHKT, SAMP, and BNKK. NTUS also possibly suffered from postseismic movement. During the first week, we can observe very rapid postseismic movement at PHKT. However this rapid movement decelerated soon and nearly stopped at the end of January, 2005 (around day $30 \sim 40$ in Fig. 2(o)). The movement at PHKT accelerated a little bit and is still going on with decay till mid-May. The total displacement before the Nias earthquake amounts to $100.4 \pm 2.3 \mathrm{~mm}$ to the west and $36.0 \pm 1.9 \mathrm{~mm}$ to the south (Table 3). We can observe similar change in postseismic displacements at this time at other sites, though the data are noisy. At NTUS and SAMP, the northward movements might have been reversed (Fig. 2(j) and (n)). They moved westward during January, and then changed their direction to WNW. We also observe acceleration of southward motion and deceleration of westward motion at CHMI and 

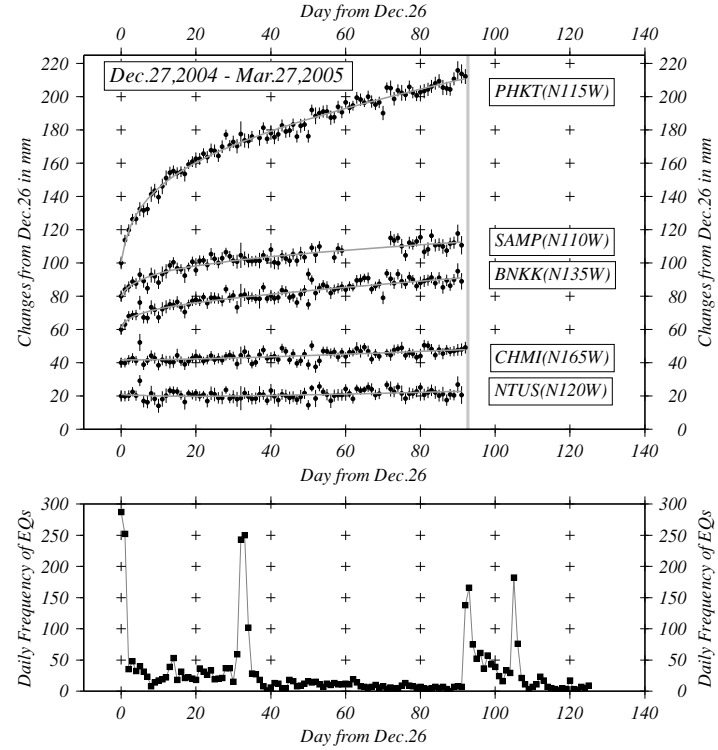

Fig. 4. Fitting of logarithmic decaying function by Marone et al. (1991) to the time series of postseismic movements at PHKT, SAMP, BNKK, CHMI and NTUS in the direction of their maximum displacement (shown on the right side of the site ID) during the period from December 27, 2004 to March 27, 2005. Gray solid lines indicate the fitted theoretical curves, respectively. Vertical gray line indicates the origin time of the Nias earthquake. Lower diagram is temporal variation in daily frequency of aftershocks observed by NEIC/USGS (2005).

BNKK at the end of January (Fig. 2(h) and (m)). We can see a step around the day 50 at PHKT. Since there are disturbances common to many sites, especially in India or Indian Ocean, it might be attributed to tropospheric or other unknown effects. Or it is possible that the changes in postseismic displacements are related to this disturbance around the day 50. So far we cannot present any conclusion and these data should be analyzed thoroughly in the future.

We try to interpret the postseismic deformations before the Nias earthquake on the basis of physics of rock friction. Since we adopt an afterslip model for the spatial distribution of postseismic displacements in the following chapter, it is reasonable to use a formula derived from rock friction experiments. Figure 4 shows the displacement at several sites projected onto the direction of the maximum displacements before the occurrence of the Nias earthquake. For example, the direction of PHKT is almost WSW (N115W). We fit the following function for time dependent afterslip derived from the experiment of rock friction by Marone $e t$ al. (1991):

$$
U_{p}(t)=\alpha \ln \left(\frac{\beta}{\alpha} t+1\right)+V_{0} t+U_{\mathrm{ref}},
$$

where $\alpha$ is the parameter related to $(a-b)$ in velocitystrengthening layer, $\beta$ is related to coseismic slip velocity, $V_{0}$ is velocity in steady state, and $U_{\text {ref }}$ is offset of displacement at the start of observation. This function is based on rate and state dependent friction law and aimed to represent time evolution of afterslip in a velocity-strengthening layer. In fitting of this function to data, we performed a grid search for $\beta / \alpha$ within a range of 0.01 to 5.0 with an interval of 0.01 . As the equation is linear for $\alpha, V_{0}$ and $U_{\text {ref }}$, we applied the
Table 3. Displacements at continuous sites during the period from December 27, 2004 to March 27, 2005.

\begin{tabular}{crrr}
\hline Site & \multicolumn{1}{c}{$\mathrm{dE}(\mathrm{mm})$} & \multicolumn{1}{c}{$\mathrm{dN}(\mathrm{mm})$} & \multicolumn{1}{c}{$\mathrm{dU}(\mathrm{mm})$} \\
\hline BAHR & $-16.7 \pm 3.3$ & $11.2 \pm 1.8$ & $11.3 \pm 4.7$ \\
BAKO & $-1.4 \pm 2.0$ & $-4.7 \pm 2.5$ & $1.6 \pm 4.9$ \\
BAN2 & $2.0 \pm 2.9$ & $3.9 \pm 1.8$ & $12.6 \pm 5.0$ \\
BNKK & $-29.1 \pm 2.1$ & $-13.0 \pm 1.6$ & $-13.7 \pm 5.1$ \\
CHMI & $-8.0 \pm 2.1$ & $-6.9 \pm 1.5$ & $-7.1 \pm 5.6$ \\
COCO & $0.4 \pm 2.1$ & $5.8 \pm 2.7$ & $2.4 \pm 3.1$ \\
DARW & $12.7 \pm 2.1$ & $9.9 \pm 2.7$ & $-41.7 \pm 5.3$ \\
DGAR & $-2.7 \pm 2.9$ & $5.3 \pm 2.4$ & $-7.9 \pm 3.2$ \\
HYDE & $-5.3 \pm 2.7$ & $9.4 \pm 1.6$ & $10.1 \pm 3.4$ \\
IISC & $-9.1 \pm 2.7$ & $7.0 \pm 1.7$ & $13.2 \pm 3.6$ \\
KUNM & $4.6 \pm 2.1$ & $7.0 \pm 1.5$ & $-28.1 \pm 7.2$ \\
NTUS & $-6.6 \pm 2.0$ & $1.1 \pm 2.1$ & $1.9 \pm 3.5$ \\
PHKT & $-100.4 \pm 2.3$ & $-36.0 \pm 1.9$ & $-0.2 \pm 5.8$ \\
PIMO & $-20.2 \pm 1.9$ & $6.4 \pm 1.6$ & $18.8 \pm 6.2$ \\
REUN & $-20.4 \pm 3.4$ & $-8.8 \pm 2.6$ & $-22.1 \pm 7.3$ \\
SAMP & $-33.6 \pm 2.1$ & $-3.7 \pm 2.0$ & $6.5 \pm 4.6$ \\
SHAO & $0.4 \pm 1.4$ & $2.6 \pm 1.4$ & $23.5 \pm 4.5$ \\
SUWN & $-7.4 \pm 1.4$ & $5.9 \pm 1.4$ & $44.3 \pm 3.7$ \\
USUD & $-18.3 \pm 1.4$ & $8.3 \pm 1.4$ & $6.3 \pm 2.8$ \\
YAR2 & $7.5 \pm 1.9$ & $4.7 \pm 3.3$ & $-12.8 \pm 4.2$ \\
YARR & $7.5 \pm 1.9$ & $5.8 \pm 3.3$ & $-7.0 \pm 3.9$ \\
\hline
\end{tabular}

least square method once $\beta / \alpha$ is fixed.

It is difficult to estimate parameters with enough confidence mainly due to the nonlinearity of this formula (Table 4). CHMI and NTUS have negative $\alpha$, which implies velocity-weakening at these sites. However displacements are so small that this formula may not be applicable to data from these sites. $\beta / \alpha$ for data for PHKT and SAMP is about 1.2 and 1.0, respectively. This implies a time constant of around 1 day. Therefore the characteristic time may be small for the postseismic displacements following the December mainshock. $V_{0}$ is not inconsistent with relative plate velocity between the Indian-Austraila plate and Sunda block (Bock et al., 2003).

In Fig. 4 we also show daily frequency of aftershocks in and around the source region for the comparison with seismicity as a stress indicator in the source region. Hypocentral data is obtained from the NEIC website (http://neic.usgs.gov/neis/epic/epic.html). There was a swarm activity in the Andaman Sea around January 26, 2005. There might be changes in trend before and after this swarm activity, for example at SAMP, but it is not significant.

On March 28, 2005, another Mw 8.7 event occurred on just SE segment of the December mainshock. In this case we simply take differences between coordinates on March 27 and 29. We can see large steps of $120.8 \pm 2.3 \mathrm{~mm}$ to the west and $134.8 \pm 2.2 \mathrm{~mm}$ to the south at SAMP (Table 5). SAMP may have uplifted by $10.8 \pm 4.8 \mathrm{~mm}$. PHKT also moved by $1.7 \pm 2.5 \mathrm{~mm}$ to the west and $16.4 \pm 2.1 \mathrm{~mm}$ to the south. BNKK shifted by $0.3 \pm 2.2 \mathrm{~mm}$ to the west and $7.5 \pm 1.7 \mathrm{~mm}$ to the south, but there is no significant movement at CHMI. There are several sites whose displacements are larger than a couple of $\mathrm{mm}$. Taking their epicentral distance into consideration, we do not regard them as real crustal deformations. 
Table 4. Estimated coefficients of Marone et al.'s (1991) function for time series of horizontal displacement at PHKT. Numerals in parentheses are confidence interval of each parameter that gives residuals larger than that of optimal estimate by its $10 \%$. Numerals with asterisks indicate that these estimates are at the limit of searching range.

\begin{tabular}{ccccc}
\hline Site & $\alpha(\mathrm{mm})$ & $\beta(\mathrm{mm} /$ day $)$ & $V_{0}(\mathrm{~mm} /$ year $)$ & $U_{\text {ref }}(\mathrm{mm})$ \\
\hline Phuket (PHKT) & $19\left(26 \sim 16^{*}\right)$ & $23\left(8 \sim 82^{*}\right)$ & $112\left(66 \sim 134^{*}\right)$ & $-8\left(4 \sim-23^{*}\right)$ \\
Sampari (SAMP) & $6\left(26 \sim 5^{*}\right)$ & $6\left(1 \sim 25^{*}\right)$ & $27\left(-55 \sim 35^{*}\right)$ & $-2\left(5 \sim-7^{*}\right)$ \\
Bangkok (BNKK) & $4\left(83^{*} \sim 4^{*}\right)$ & $18\left(0^{*} \sim 18^{*}\right)$ & $49\left(-122^{*} \sim 49^{*}\right)$ & $-3\left(6^{*} \sim-3^{*}\right)$ \\
Chaingmai (CHMI) & $-2\left(-15^{*} \sim 0^{*}\right)$ & $0\left(0^{*} \sim-2^{*}\right)$ & $41\left(65^{*} \sim 30^{*}\right)$ & $2\left(2^{*} \sim 2^{*}\right)$ \\
Singapore (NTUS) & $-2\left(-22^{*} \sim 0^{*}\right)$ & $0\left(0^{*} \sim-4^{*}\right)$ & $28\left(67^{*} \sim 20^{*}\right)$ & $1\left(0^{*} \sim 2^{*}\right)$ \\
\hline
\end{tabular}

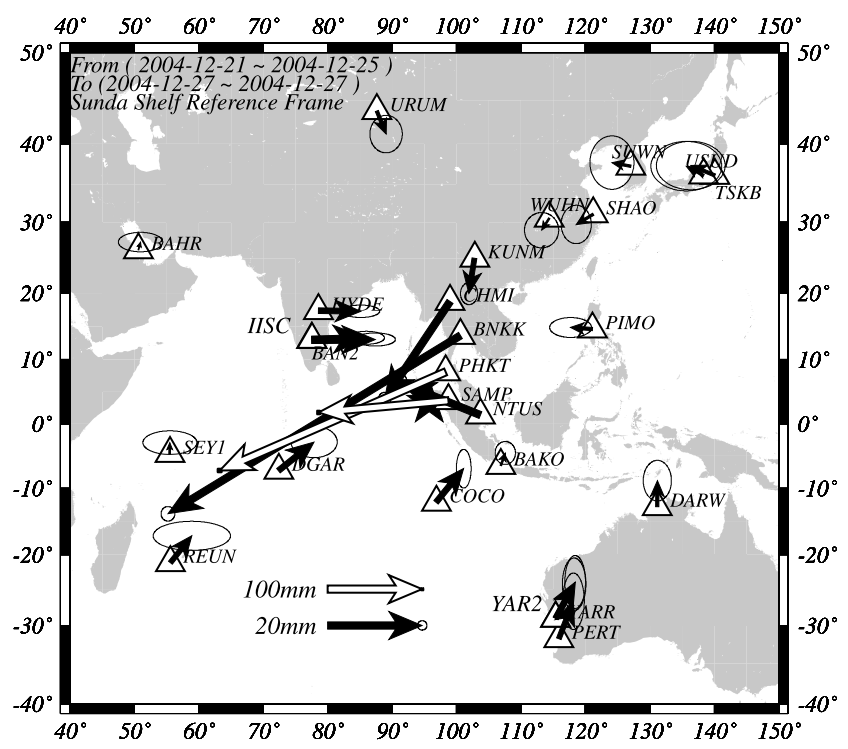

Fig. 5. Estimated coseismic displacements from the Sumatra-Andaman earthquake. A star shows the epicenter of the December mainshock. Error ellipses show 1-sigma. Notice the scale for PHKT and SAMP is 5 times larger than that for other sites.

Postseismic displacement from the Nias earthquake is also recognized at SAMP and NTUS (Fig. 2(j) and 2(o), Table 6). It is superposed on that following the mainshock, but we can certainly recognize as the rapid increase of rate. No significant change in rate of postseismic movement is seen at PHKT.

\section{Spatial Distribution of Displacements and Their Fault Models}

In the following sections, we discuss spatial distribution of coseismic and postseismic displacements associated with the Sumatra-Andaman earthquake. We adopt an afterslip model for postseismic displacements. There are many studies of postseismic displacements with afterslip model (e.g. Heki et al., 1997; Yagi et al., 2001; Miyazaki et al., 2004; Miura et al., 2005). We assume a half space in order to focus on the displacements in northern Sumatra, Thailand and Singapore using Okada's (1985) formula. If we discuss the displacements at far sites, the sphericity of the Earth must be considered due to the scale of rupture (Banerjee et al., 2005). However Banerjee et al. (2005) showed that effect of sphericity might be cancelled when stratified earth is assumed. Furthermore outer core of the earth is important for the displacements at sites as far as $5,000 \mathrm{~km}$ away, but the assumption of liquid outer core causes numerical problems.

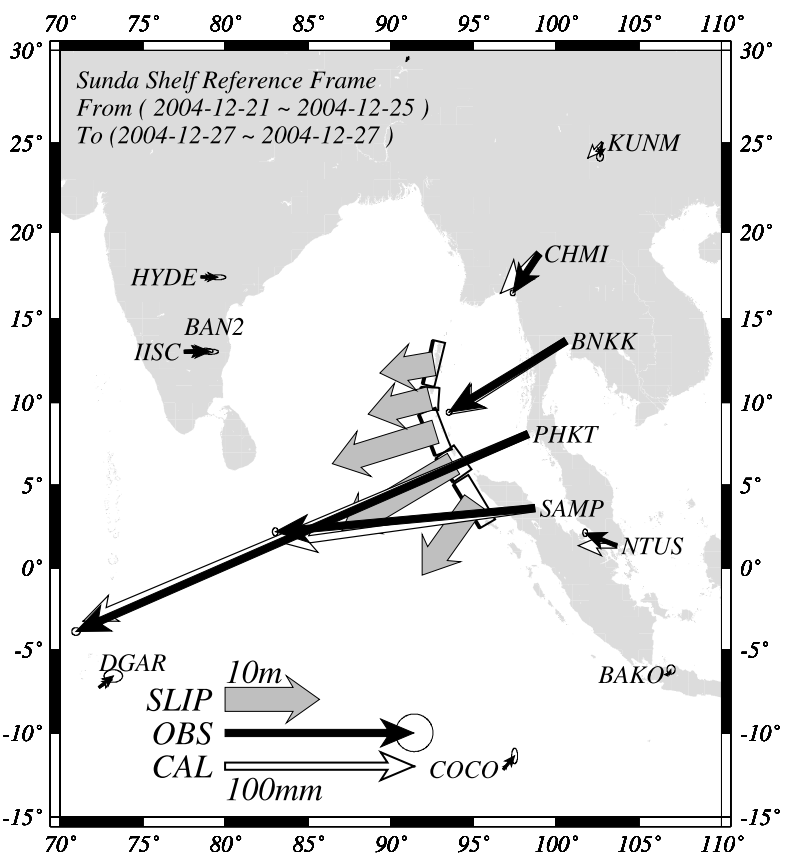

Fig. 6. Close-up of the coseismic displacements from the Sumatra-Andaman earthquake in Southeast Asia. Solid and open arrows show observed and calculated displacements for the optimal model, respectively. Rectangles are surface projections of assumed fault segments whose upper margins are indicated by thick lines. Thick arrows are the estimated slip on each segment.

Therefore modeling with spherical earth model must be the future problem and we adopt a half space model.

We assume multi-segment model for the source fault. We tried to find slips on segments by fitting observed displacements with the following smoothness condition on slips:

$$
D_{i+1}-2 D_{i}+D_{i-1}=\delta,
$$

where $D_{i}$ is strike- or dip-slip component on i-th segment. We assume $\delta$ obeys normal distribution with standard deviation of $\sigma . \sigma$ is used as a weight for this smoothness condition in the observation equation. This condition assumes differences between neighboring segments may not vary so much.

\subsection{Coseismic displacements from the December 26, 2004 earthquake}

The coseismic displacement field from the mainshock is shown in Figs. 5 and 6 . Note that the scale of displacements at PHKT and SAMP is 5 times larger than that for other sites in Fig. 5. Figure 6 shows the close-up of the region around the epicenter. Most sites with significant displacement moved toward the source region. Stations on the 
Table 5. Coseismic displacements at continuous GPS sites from the March 28 Nias earthquake.

\begin{tabular}{crrr}
\hline Site & \multicolumn{1}{c}{$\mathrm{dE}(\mathrm{mm})$} & \multicolumn{1}{c}{$\mathrm{dN}(\mathrm{mm})$} & \multicolumn{1}{c}{$\mathrm{dU}(\mathrm{mm})$} \\
\hline BAHR & $-2.9 \pm 3.6$ & $0.1 \pm 1.9$ & $-0.9 \pm 4.3$ \\
BAKO & $0.2 \pm 2.1$ & $-0.8 \pm 2.7$ & $-4.8 \pm 5.0$ \\
BAN2 & $-1.7 \pm 3.1$ & $5.5 \pm 2.0$ & $-3.8 \pm 5.2$ \\
BNKK & $0.3 \pm 2.2$ & $-7.5 \pm 1.7$ & $7.4 \pm 5.2$ \\
CHMI & $-0.4 \pm 2.3$ & $-0.5 \pm 1.5$ & $3.2 \pm 6.2$ \\
COCO & $-1.2 \pm 2.3$ & $2.2 \pm 3.0$ & $-6.4 \pm 3.3$ \\
DARW & $-9.8 \pm 2.1$ & $4.8 \pm 3.1$ & $4.7 \pm 5.9$ \\
DGAR & $3.7 \pm 3.1$ & $-3.7 \pm 2.6$ & $-17.6 \pm 3.4$ \\
HYDE & $1.6 \pm 2.9$ & $-0.2 \pm 1.7$ & $-4.5 \pm 3.5$ \\
IISC & $0.6 \pm 3.0$ & $1.0 \pm 1.9$ & $-3.7 \pm 3.6$ \\
KUNM & $-9.4 \pm 2.1$ & $-7.4 \pm 1.4$ & $37.4 \pm 7.3$ \\
LHAS & $-1.6 \pm 2.5$ & $2.5 \pm 1.4$ & $3.7 \pm 5.4$ \\
NTUS & $-13.3 \pm 2.1$ & $-2.4 \pm 2.3$ & $0.2 \pm 3.6$ \\
PHKT & $-1.7 \pm 2.5$ & $-16.4 \pm 2.1$ & $-19.0 \pm 6.4$ \\
REUN & $1.4 \pm 3.6$ & $-0.7 \pm 2.8$ & $6.9 \pm 7.6$ \\
SAMP & $-120.8 \pm 2.3$ & $-134.8 \pm 2.2$ & $10.8 \pm 4.8$ \\
SHAO & $5.9 \pm 1.4$ & $-3.5 \pm 1.4$ & $-9.9 \pm 4.7$ \\
SUWN & $5.9 \pm 1.4$ & $-4.1 \pm 1.4$ & $-2.4 \pm 2.8$ \\
USUD & $5.1 \pm 1.4$ & $-4.1 \pm 1.4$ & $2.1 \pm 2.8$ \\
YAR2 & $-6.5 \pm 1.9$ & $1.5 \pm 3.7$ & $9.3 \pm 4.3$ \\
YARR & $-6.8 \pm 1.9$ & $0.9 \pm 3.7$ & $2.5 \pm 4.0$ \\
\hline & & &
\end{tabular}

Table 6. Displacements at continuous sites during the period from March 29 to May $15,2005$.

\begin{tabular}{crrr}
\hline Site & \multicolumn{1}{c}{$\mathrm{dE}(\mathrm{mm})$} & \multicolumn{1}{c}{$\mathrm{dN}(\mathrm{mm})$} & \multicolumn{1}{c}{$\mathrm{dU}(\mathrm{mm})$} \\
\hline BAHR & $2.9 \pm 6.5$ & $-4.3 \pm 7.0$ & $7.8 \pm 32.8$ \\
BAKO & $-9.4 \pm 5.4$ & $1.5 \pm 2.8$ & $23.6 \pm 11.3$ \\
BAN2 & $-2.6 \pm 3.4$ & $-2.2 \pm 3.2$ & $1.5 \pm 8.6$ \\
BNKK & $-12.9 \pm 1.9$ & $-6.6 \pm 1.8$ & $11.7 \pm 11.0$ \\
COCO & $1.3 \pm 2.6$ & $7.5 \pm 2.9$ & $6.1 \pm 10.1$ \\
DARW & $-5.5 \pm 2.8$ & $10.0 \pm 3.5$ & $26.8 \pm 7.4$ \\
DGAR & $1.0 \pm 3.8$ & $3.3 \pm 2.6$ & $14.8 \pm 10.7$ \\
HYDE & $-2.8 \pm 2.5$ & $3.7 \pm 1.5$ & $5.9 \pm 3.1$ \\
IISC & $-3.8 \pm 2.7$ & $3.5 \pm 1.7$ & $-29.2 \pm 5.2$ \\
KUNM & $-1.4 \pm 1.8$ & $-7.4 \pm 2.6$ & $10.1 \pm 8.9$ \\
LHAS & $-1.1 \pm 3.1$ & $-5.4 \pm 2.9$ & $6.9 \pm 5.0$ \\
NTUS & $-12.6 \pm 2.7$ & $-1.2 \pm 2.8$ & $9.0 \pm 6.7$ \\
PHKT & $-22.4 \pm 2.1$ & $-16.9 \pm 2.8$ & $6.4 \pm 7.2$ \\
REUN & $1.9 \pm 3.3$ & $1.9 \pm 3.4$ & $16.7 \pm 12.6$ \\
SAMP & $-53.9 \pm 2.1$ & $-52.2 \pm 2.1$ & $0.0 \pm 8.3$ \\
SHAO & $-1.4 \pm 1.9$ & $-3.2 \pm 2.8$ & $2.7 \pm 5.2$ \\
SUWN & $-5.1 \pm 2.8$ & $0.3 \pm 4.3$ & $-7.3 \pm 4.9$ \\
TSKB & $-4.2 \pm 4.4$ & $-2.0 \pm 3.8$ & $-23.1 \pm 11.0$ \\
WUHN & $-3.9 \pm 2.6$ & $-2.1 \pm 1.6$ & $9.2 \pm 6.0$ \\
YAR2 & $0.4 \pm 1.8$ & $12.7 \pm 4.3$ & $8.3 \pm 4.6$ \\
YARR & $0.7 \pm 1.8$ & $13.3 \pm 4.1$ & $10.2 \pm 6.7$ \\
\hline & & &
\end{tabular}

east side of the epicenter moved westward, while those on the west side shifted eastward. KUNM in the north moved southward. As we previously pointed out, BAKO in Indonesia and LHAS in Tibet have small displacements for their epicentral distances, which implies they are located close to the nodal line of the displacement distribution due to thrust faulting. Direction of displacements at BNKK and CHMI is more southward than that of PHKT.

Several groups have already proposed fault models for the Sumatra-Andaman and Nias earthquakes on the basis of seismograms, tsunami, radar images, and geodetic mea-

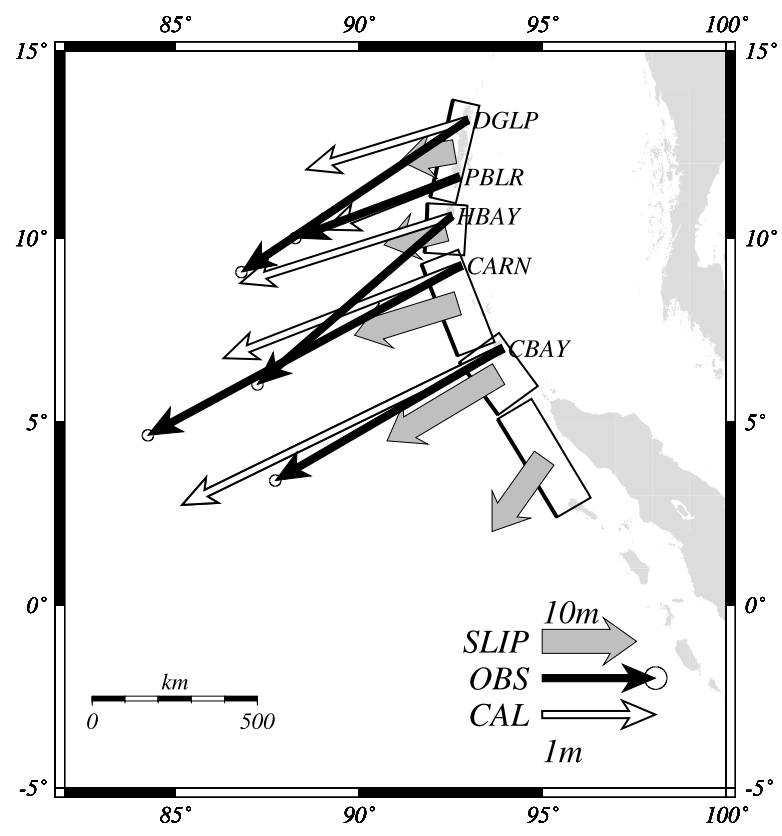

Fig. 7. Comparison of calculated displacements for the optimal fault model (open arrows) with the observed ones by Earnest et al. (2005) (solid arrows)

surements etc. (Yagi, 2005; Yamanaka, 2005; Ammon et al., 2005; Banerjee et al., 2005; Vigny et al., 2005). Common features in already presented models are as follows:

(1) Large slip on the southern half segments,

(2) Pure thrust slip on the southern half, while large right lateral motions are estimated on the northern half.

Since we have no data on the Andaman and Nicobar Islands or northern Sumatra except SAMP, it is hard to resolve slip distribution with enough resolving power. Therefore we adopt a multi-segment model with uniform slip to reduce the number of model parameters. Suito et al. (2005) presented a five segment model with uniform slip to explain the pattern of vertical deformations in Andaman and Nicobar Islands and northern Sumatra which are derived from intensity changes in InSAR images obtained before and after the events (Tobita et al., 2005). Suito et al. aligned segments along the Sumatra-Andaman trench, and adopted dip and rake of Harvard CMT solutions. They adjusted slips on the segments to fit the pattern of the calculated vertical displacement distribution to the observations. They also made the total moment calculated from the fault model consistent with CMT. We adopt their model as a starting model.

First we simply calculated the displacements for Suito et al.'s model of the Sumatra-Andaman earthquake of December 26, 2004, but their model fails to explain the displacements at PHKT and SAMP. Their model underestimates displacement at PHKT, but overestimates at SAMP. It can be attributed to relatively small slip on the segment just south of Nicobar Island. We try to find slips on segments changing width and dip of segments. In this case we adopt $5 \mathrm{~m}$ for the weight of smoothness condition. In fitting, we use observed displacements in Andaman and Nicobar islands by Earnest and Rajendran (2005). They conducted GPS surveys at 5 sites (Fig. 1(b)) in Andaman and Nicobar Islands in September, 2004 and January, 2005. Since 
Table 7. Fault parameters used in modeling of observed crustal deformations. Lat. and Lon. denote latitude and longitude of a corner of fault, respectively. L, W, and $\mathrm{H}$ are length, width and depth of the upper margin of fault in $\mathrm{km}$, respectively. Strike is measured clockwise from the north. $\mathrm{U}$ is slip in $\mathrm{m}$. Mo is seismic moment in $\mathrm{Nm}$ using rigidity of $40 \mathrm{GPa}$ and $\mathrm{Mw}$ is moment magnitude.

(a) Fault model for coseismic displacements from the December 26, 2004, Sumatra-Andaman earthquake

\begin{tabular}{rrrrrrrrrrrrrr}
\hline Lat. & Lon. & \multicolumn{1}{c}{ L } & W & H & Strike & Dip & Us & Ud & Rake & U & Mo & Mw \\
\hline 2.40 & 95.40 & 350 & 120 & 10 & 330 & 8 & $-3.96 \pm 0.87$ & $8.73 \pm 0.49$ & 114.39 & 9.59 & $1.61 \times 10^{22}$ & 8.74 \\
5.20 & 93.80 & 200 & 150 & 10 & 325 & 8 & $0.99 \pm 1.56$ & $13.84 \pm 1.23$ & 85.93 & 13.88 & $1.67 \times 10^{22}$ & 8.75 \\
6.80 & 92.70 & 300 & 120 & 10 & 340 & 8 & $0.56 \pm 1.39$ & $11.55 \pm 1.23$ & 87.24 & 11.56 & $1.66 \times 10^{22}$ & 8.75 \\
9.60 & 91.80 & 150 & 120 & 10 & 5 & 8 & $-2.21 \pm 1.57$ & $6.41 \pm 1.48$ & 109.03 & 6.78 & $4.88 \times 10^{21}$ & 8.39 \\
11.10 & 91.95 & 300 & 80 & 10 & 15 & 8 & $-2.43 \pm 1.27$ & $5.32 \pm 1.32$ & 114.55 & 5.85 & $5.61 \times 10^{21}$ & 8.43 \\
Total & & & & & & & & & & $5.99 \times 10^{22}$ & 9.12 \\
\hline
\end{tabular}

(b) Fault model for postseismic displacements during December 27, 2004, to March 27, 2005

\begin{tabular}{rcccccccccccc}
\hline \multicolumn{1}{c}{ Lat. } & Lon. & L & W & H & Strike & Dip & Us & Ud & Rake & U & Mo \\
\hline 2.40 & 95.40 & 350 & 220 & 10 & 330 & 8 & $-1.58 \pm 0.54$ & $1.65 \pm 0.42$ & 133.89 & 2.29 & $7.04 \times 10^{21}$ & 8.50 \\
5.20 & 93.80 & 200 & 220 & 10 & 325 & 8 & $0.16 \pm 1.17$ & $1.96 \pm 0.74$ & 85.30 & 1.97 & $3.46 \times 10^{21}$ & 8.29 \\
6.80 & 92.70 & 300 & 220 & 10 & 340 & 8 & $0.90 \pm 1.25$ & $1.74 \pm 0.82$ & 62.55 & 1.96 & $5.17 \times 10^{21}$ & 8.41 \\
9.60 & 91.80 & 150 & 220 & 10 & 5 & 8 & $0.54 \pm 0.97$ & $1.65 \pm 0.83$ & 71.76 & 1.74 & $2.30 \times 10^{21}$ & 8.17 \\
11.10 & 91.95 & 300 & 220 & 10 & 15 & 8 & $-0.39 \pm 1.59$ & $1.82 \pm 1.05$ & 102.16 & 1.86 & $4.91 \times 10^{21}$ & 8.39 \\
Total & & & & & & & & & & & $2.29 \times 10^{22}$ & 8.84 \\
\hline
\end{tabular}

(c) Fault model for coseismic displacements from the March 28, 2005, Nias earthquake

\begin{tabular}{ccccccccccccc}
\hline Lat. & Lon. & L & W & H & Strike & Dip & Us & Ud & Rake & U & Mo & Mw \\
\hline-0.25 & 97.60 & 330 & 120 & 10 & 329 & 14 & $-1.37 \pm 0.38$ & $3.36 \pm 0.26$ & 112.21 & 3.62 & $5.74 \times 10^{21}$ & 8.44 \\
\hline
\end{tabular}

(d) Fault model for postseismic displacement during March 29 to May 15, 2005

\begin{tabular}{rrrrrrrrrrrrrr}
\hline Lat. & Lon. & L & W & H & Strike & Dip & \multicolumn{1}{c}{ Us } & Ud & Rake & U & Mo & Mw \\
\hline-0.25 & 97.60 & 330 & 220 & 10 & 329 & 14 & $0.41 \pm 0.19$ & $0.67 \pm 0.11$ & 58.73 & 0.79 & $2.28 \times 10^{21}$ & 8.17 \\
2.40 & 95.40 & 350 & 220 & 10 & 330 & 8 & $-0.80 \pm 0.35$ & $0.63 \pm 0.27$ & 141.75 & 1.02 & $3.16 \times 10^{21}$ & 8.27 \\
5.20 & 93.80 & 200 & 220 & 10 & 325 & 8 & $-1.37 \pm 0.70$ & $0.55 \pm 0.32$ & 158.17 & 1.47 & $2.59 \times 10^{21}$ & 8.21 \\
6.80 & 92.70 & 300 & 220 & 10 & 340 & 8 & $-1.26 \pm 0.70$ & $0.49 \pm 0.43$ & 158.67 & 1.35 & $3.58 \times 10^{21}$ & 8.30 \\
9.60 & 91.80 & 150 & 220 & 10 & 5 & 8 & $-0.65 \pm 0.51$ & $0.65 \pm 0.43$ & 134.86 & 0.92 & $1.21 \times 10^{21}$ & 7.99 \\
11.10 & 91.95 & 300 & 220 & 10 & 15 & 8 & $0.17 \pm 1.02$ & $0.97 \pm 0.58$ & 80.30 & 0.98 & $2.60 \times 10^{21}$ & 8.21 \\
Total & & & & & & & & & & & & & \\
\hline
\end{tabular}

Table 8. Comparison of calculated displacements at sites in Andaman and Nicobar Islands for the optimal model in Table 7(a) with the observation by Earnest and Rajendran (2005). Displacements are in m. Digits in parenthesis are observed displacements.

\begin{tabular}{lccc}
\hline Site & Eastward & Northward & Uplift \\
\hline Diglipur (DGLP) & $-3.01(-3.99)$ & $-0.88(-2.68)$ & $0.17(0.63)$ \\
Port Blair (PBLR) & $-2.41(-2.89)$ & $-0.96(-1.08)$ & $-0.74(-0.57)$ \\
Hut Bay (HBAY) & $-3.78(-3.43)$ & $-1.16(-2.97)$ & $0.28(0.36)$ \\
Carl Nicobar (CARN) & $-4.49(-5.53)$ & $-1.64(-2.99)$ & $-1.36(-1.05)$ \\
Campbell Bay (CBAY) & $-5.98(-4.01)$ & $-2.84(-2.33)$ & $-1.22(-1.36)$ \\
\hline
\end{tabular}

displacements in these islands are larger than those in Thailand by a factor of $20 \sim 100$, we pose very small weights on them so that the model fits displacements in Thailand better. However we change the width of segments in order to fit subsidence at Port Blair and Carl-Nicobar etc. Open arrows in Fig. 6 show the calculated displacements for the optimal model. This model can explain observed displacements in Thailand and at SAMP well. This model also fairly explains the deformation in Andaman and Nicobar Islands (Fig. 7, Table 8). We obtained as large slip as $14 \mathrm{~m}$ on the segments beneath the Nicobar Islands (Table 7(a)). Slip on the southernmost segment, in which the hypocenter of the mainshock is located, was estimated at about $9.6 \mathrm{~m}$. On the other hand, slips are not larger than $7 \mathrm{~m}$ beneath the Andaman Islands. We decreased the width beneath the northern Andaman segment in this model, while the segments beneath the Nicobar Islands were widened in order to explain subsidence at Port Blair in northern Andaman, Carl Nicobar, and Campbell Bay. This modification does not affect the displacements in Thailand so much. If we remove segments beneath Andaman Islands, the fit is degraded. Thus models without segments beneath the Andaman Islands cannot explain the deformation in these islands. When we increase the dip of the fault to $10 \mathrm{deg}$, residuals increase slightly. Therefore we do not take steeper dip angles. Resultant moment for the optimal model is $5.99 \times 10^{22} \mathrm{Nm}$ and $\mathrm{Mw}$ is 9.12 , if rigidity of $40 \mathrm{GPa}$ is adopted.

\subsection{Postseismic displacements following the main-} shock before the Nias earthquake

Figure 8 shows the postseismic displacement field during the period following the mainshock and before the Nias earthquake. We can see a large SW ward displacement at PHKT and a westward displacement at SAMP during both periods. It is noteworthy that the ratio of displacements at PHKT to that at SAMP is larger than 3, while the ratio for the coseismic displacements of these two sites was about 2 . Therefore it is obvious that the spatial distribution of afterslip is different from that of coseismic slip, if the afterslip 


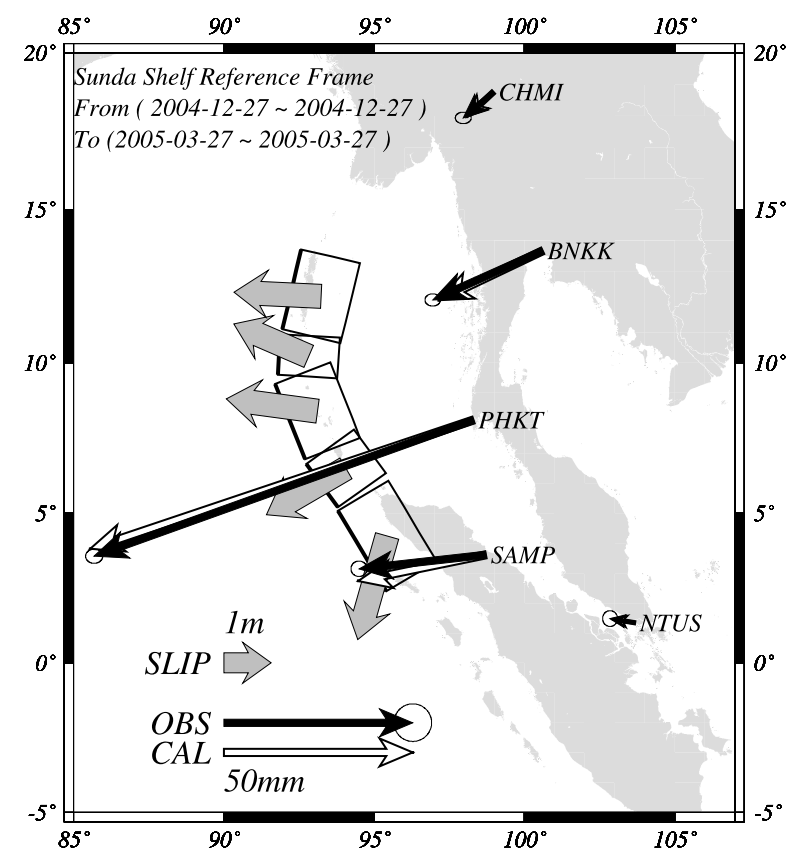

Fig. 8. Postseismic displacement field in southern Asia during the period from December 26, 2004 and March 27, 2005. Solid and open arrows show observed and calculated displacements for the optimal model, respectively. Rectangles are surface projections of assumed fault segments whose upper margins are indicated by thick lines. Thick arrows are estimated slips on each segment.

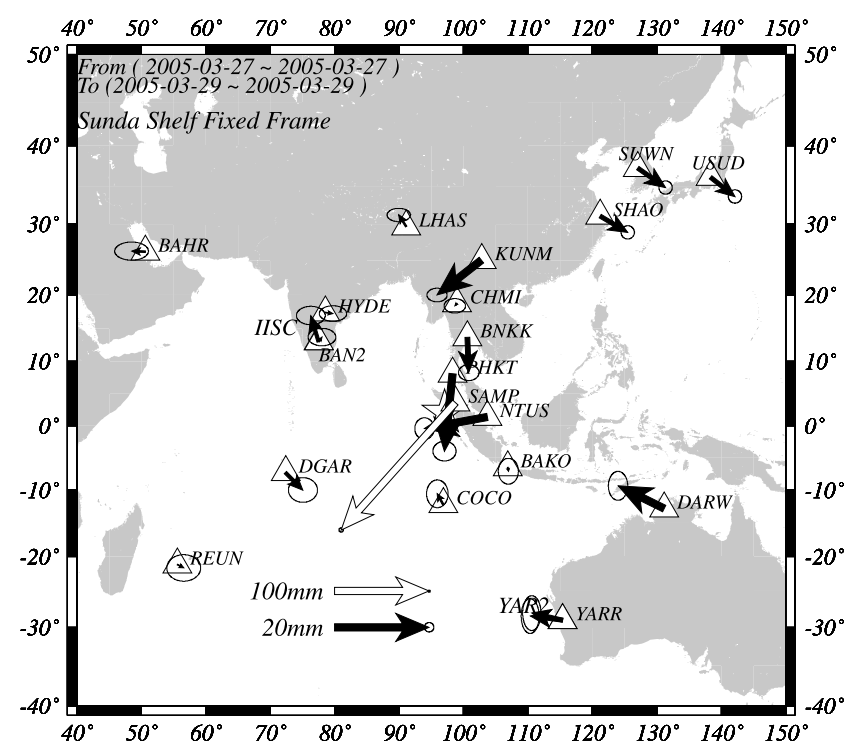

Fig. 9. Coseismic displacements from the March 28, 2005, Nias earthquake. Stars show the epicenters of the December mainshock and Nias event. Notice that the sacle for SAMP is 5 times larger than that for others.

model is adopted.

We also tried to fit postseismic displacements following the December mainshock again based on the Suito et al.'s fault model. However we made the width of the fault larger in order to take diffusion of afterslip to the deep extension of the coseismic fault into consideration (Table 7(b)). Since we have no quantitative information on postseismic deformation in Andaman-Nicobar Islands and precise hypocentral distribution of aftershocks so far, we assume the same

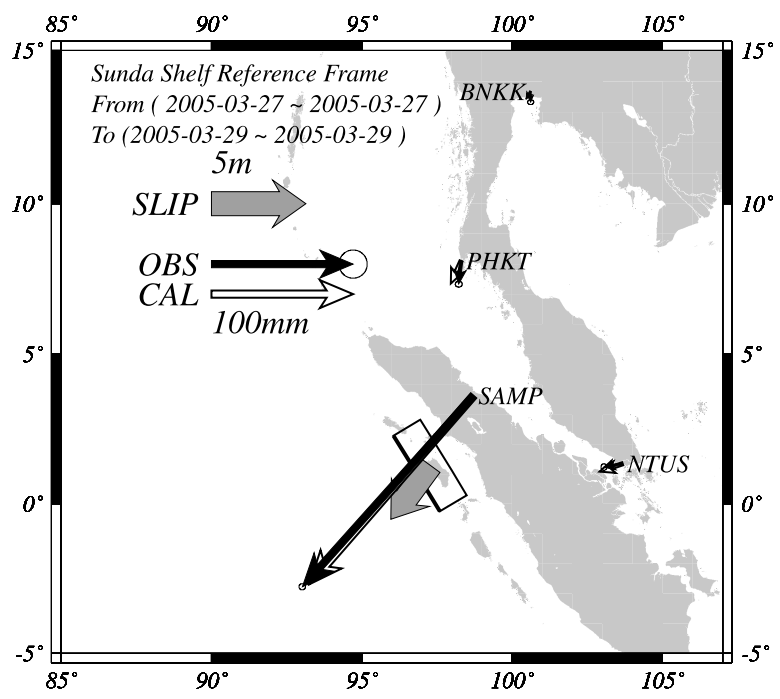

Fig. 10. Close-up of the coseismic displacements from the Nias earthquake in Southeast Asia. Solid and open arrows show observed and calculated displacements for the optimal model, respectively. Rectangle is the surface projection of assumed fault plane whose upper margin is indicated by thick line. Thick arrow is the estimated slips on each segment.

width for all segments. We tried three cases for width of 180,200 and $220 \mathrm{~km}$ for the fitting of postseismic deformations, and chose the optimal value by comparing the residuals. As we found a change in rate and pattern of the postseismic displacement field, we fit the observed displacements in the two periods separately. Fitting data during the first period till the end of January, we must pose a little large constraint $(\sim 1 \mathrm{~m})$ on the smoothing condition. If not, we obtained physically unreasonable solutions with normal faulting on a couple of segments. In this case we chose $220 \mathrm{~km}$ for width of fault. Figure 8 shows the result of fitting. Large slips of $2.0 \mathrm{~m}$ on the segments south of Nicobar Island were obtained. Thus spatial distribution of afterslip is different from that of coseismic slip. We also obtained afterslips of about $1.8 \mathrm{~m}$ on the two segments beneath the Andaman Islands, but the rakes for these segments are different from those for the mainshock. We checked that slips on these segments do not largely affect the displacements at Thai sites by forward calculations. Therefore we can conclude that postseismic displacement before the Nias earthquake can be explained mainly by afterslip on the southern segments. Total moment released by afterslip during this period is estimated $2.29 \times 10^{22} \mathrm{Nm}$ (Mw 8.84). This amounts to $38 \%$ of seismic moment released during the mainshock.

\subsection{Coseismic displacements from the March 28, 2005, Nias earthquake}

Significant coseismic displacements from the Nias earthquake can be recognized only at SAMP, PHKT, BNKK and NTUS (Figs. 9 and 10). SAMP moved toward the epicenter (SW-ward). This is much larger than that from the December mainshock, since the epicentral distance is much shorter in this case. Due to longer epicentral distance than SAMP, PHKT has a much smaller coseismic displacement than SAMP. Marginal eastward shifts recognized at most sites may be attributed to unknown errors in the present net- 
work that could not be eliminated by the spatial filter.

Coseismic fault models of the Nias earthquake are also presented in Fig. 10. They suggest a rather simple rupture on a single segment. We also utilize Suito et al.'s model here (Table 7(c)). However their model predicts much larger displacement at SAMP than the observation. It is simply because their estimated slip is too large. Fitting the coseismic displacements we obtained the slip of $3.6 \mathrm{~m}$. This earthquake did not cause as large a tsunami as the December mainshock. We investigate the possibility of intraplate event with high-angled thrust motion, but this model predicts a slightly larger displacement at SAMP. Of course, the calculated displacement strongly depends on the location and geometry of the fault, and its slip distribution. However we could not find any subtle evidence that the Nias earthquake is an intraplate event from GPS data. Geodetic magnitude is estimated 8.44 for this model. This is significantly smaller than that of CMT.

\subsection{Postseismic displacements following the Nias earthquake}

Following the Nias earthquake significant postseismic displacements are also observed at SAMP, PHKT and NTUS. SAMP has moved by $53.9 \pm 2.1 \mathrm{~mm}$ to the west and $52.2 \pm 2.1 \mathrm{~mm}$ to the south toward the epicenter of the Nias earthquake (Fig. 11). On the other hand, PHKT has been shifted toward the Nicobar Island. These directions of postseismic displacement suggest that postseismic deformations following the Sumatra-Andaman and Nias earthquakes dominated at PHKT and SAMP, respectively, though both effects are superposed on each other.

We also fit the postseismic displacements following the Nias earthquake. In this case we selected the segments for the Nias mainshock to $220 \mathrm{~km}$ as well as the case for the postseismic deformation following the December mainshock (Table 7(d)). We obtained an afterslip of about 65 $\mathrm{cm}$ on the segment of the Nias mainshock, which is mainly responsible for the displacement at SAMP (Fig.11). Other segments may also have afterslip ranging from $0.8 \sim 1.5 \mathrm{~m}$ with relatively large strike-slip component except the northernmost one. An unusual slip of $1.0 \mathrm{~m}$ was estimated for the northernmost segment, but we guess this segment has little contribution to the displacement in Thailand. Total seismic moment may amount to $1.54 \times 10^{22} \mathrm{Nm}$. If we neglect the slip on the northernmost segment, it reduces to $1.28 \times 10^{22}$ $\mathrm{Nm}$, which is equivalent to $\mathrm{Mw} 8.67$. It is certain that we still need afterslip equivalent to $\mathrm{Mw} 8$ or larger in order to explain the observed postseismic deformations.

\section{Discussions}

One of the important roles of geodetic observation is to estimate the static moment release of earthquake. The December 26, 2004, Sumatra-Andaman earthquake is the largest event during 40 years since the 1964 Alaska earthquake. Therefore it is essential for seismologists and geodesists to determine its size as precisely as possible. Its estimated size ranges from 8.5 to 9.3 according to the data used in the analysis. Most estimates based on seismic waves are smaller than 9.0 (Yamanaka, 2005; Yagi, 2005; Lay et al., 2005; Ammon et al., 2005; Wu and Koketsu, 2005). Banerjee et al. (2005) estimated that the static moment release did

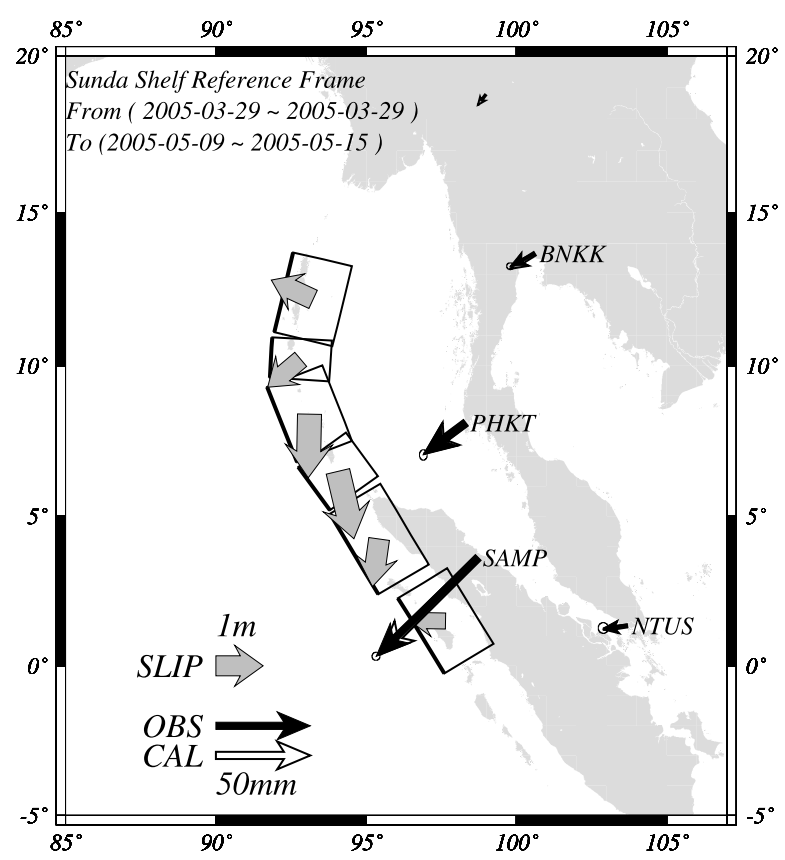

Fig. 11. Postseismic displacement field in southern Asia during the period from March 29 to May 15, 2005. Solid and open arrows show observed and calculated displacements for the optimal model, respectively. Rectangles are surface projections of assumed fault segments whose upper margins are indicated by thick lines. Thick arrows are estimated slips on each segment.

not exceed Mw 9.2. However their estimate is based on farfield displacements. The nearest site used in their analysis is SAMP that we also used. Earnest and Rajendran (2005) presented coseismic displacements in Andaman-Nicobar islands. Banerjee et al. (2005) compares theoretical displacements for their model with Rajendran et al.'s (2005) observation and estimated a total static moment magnitude of 9.14. Vigny et al. (2005) also estimated the static seismic moment magnitude as 9.2. They used GPS data from Thailand and Malaysia, some of which we also used. Our estimate is 9.12, which is equivalent to those of the other geodetic models. The largest estimate of 9.3 was derived from earth's free oscillation data (Stein and Okal, 2005), while Park et al. (2005) estimated a seismic moment magnitude of 9.15 also using free oscillation data. Usually static seismic moment is the largest estimate among those derived from various methods, but this is not the case here. A couple of estimates based on earth's free oscillation are larger than static seismic moment estimates. Park et al. (2005) indicated that the fitness to earth's free oscillation data is improved by making dip angle steeper than that of Harvard CMT solution with smaller seismic moment. Ishihara and Suda (2005) also changed dip angle to 10 degree, but they obtained twice larger seismic moment than that of Harvard CMT. According to their estimates, steeper dip angle is favorable. This discussion may affect the modeling of static displacement field. When we use dip angles of 10 degree, we obtained almost similar results with slightly larger residuals. As Bajernee et al. (2005) shows we obtain smaller slips with steeper dip angles and eventually smaller magnitude. Therefore we suspect that the estimates based on free oscillation might be overestimated. This issue should 
be thoroughly discussed in the future.

Another important role of geodesy is to reveal the spatial distribution of coseismic slips and possible afterslip responsible for postseismic deformations. As mentioned previously, most seismological observations underestimate the size of the December 26, 2004, Sumatra-Andaman earthquake. Slip is mainly found in the southern half of the aftershock distribution from the seismological observation. However Rajendran et al. (2005) revealed as large crustal deformation as $6 \mathrm{~m}$ in the Andaman and Nicobar Islands during the period from September, 2004 to January, 2005. Ikeda et al. (2005) found large eastward tilting of the Great Andaman Island on the basis of surveys of microatolls or oysters. Tobita et al. (2005) also found the same characteristics in the crustal deformations in Great Andaman Island using the change of amplitude of scattered waves detected by the InSAR satellites before and after the December mainshock. Shishikura and Tsuchida (2005) also detected a tilt of Great Andaman Island using ASTER data. Therefore large crustal deformations were definitely caused in the Andaman Island by the December mainshock. Since seismological observations cannot reveal the large slip beneath the Andaman Island, most researchers suspect that slow slip with a longer time constant than $600 \mathrm{sec}$ is responsible for the crustal deformations in Andaman Island (e.g. Bilham, 2005). Vigny et al. (2005) also show that larger slips than $10 \mathrm{~m}$ are necessary beneath the little Andaman Island to fit the displacements at GPS sites in northern Thailand. However we suppose their model may predict uplift around the Nicobar Islands, since large slip is assumed on the deep part in their fault model. Banerjee et al. (2005) show that slip beneath the Andaman Island is necessary in order to explain the coseismic displacements of far-field sites. By introducing the results by Rajendran et al. (2005) we also revealed a large slip beneath the Andaman Islands. The problem is its time constant. Whether a slow-slip occurred beneath the Andaman Island is still controversial. Vigny et al. (2005) analyzed continuous GPS data from mainly Thailand and Malaysia on December 26 using kinematic GPS, and ruled out the possibility of slow or silent slip with a period $>600 \mathrm{~s}$. However, their analysis is limited for about $60 \mathrm{~min}$ before and after the mainshock. Therefore we need a high sampling analysis of GPS data during the whole day of the mainshock.

Large postseismic deformations follow the mainshock. Total moment released by the afterslip may amount to $3.83 \times 10^{22} \mathrm{Nm}$, which is equivalent to $\mathrm{Mw} 8.99$ for about five months, including the afterslip for the Nias earthquake. It amounts to about $64 \%$ of coseismic moment of the December mainshock. Since we could not resolve afterslip beneath the Andaman Island well, this value may be overestimated. However, we can expect such a high moment release based on the crustal deformations in Thailand, as long as we adopt afterslip on the coseismic fault and its surroundings. Recent observations of postseismic deformations following the large interplate earthquakes show that significant moment is released by afterslip (e.g. Heki et al., 1997; Yagi et al., 2001; Miyazaki et al., 2004; Miura et al., 2005). Heki et al. (1997) showed that seismic moment equivalent to Mw 7 was released by afterslip following the 1994 Sanriku earth- quake of Mw 7.5. Yagi et al. (2001) also showed a similar relationship between coseismic and postseismic moment release for the 1996 Hyuganada earthquakes. Miyazaki et al. (2004) presented that afterslip released seismic moment equivalent to Mw 7.7 during 30 days following the 2003 Tokachi-oki earthquake. Therefore it is not unreasonable for afterslip to release larger moment than that of $\mathrm{Mw} 8.5$ or larger following the 2004 Sumatra-Andaman earthquake.

We showed that spatial distribution of afterslip is different from that of slip during the mainshock, if afterslip is mainly responsible. In most interplate earthquakes afterslip occurs around the coseismic rupture (e.g. Yagi et al., 2001; Miyazaki et al., 2004; Miura et al., 2005). It is an interesting topic how far the afterslip extends. Unfortunately most continuous GPS sites are located in remote regions and they have less resolving power of the afterslip. Afterslips till the end of January are large on the segments beneath the Nicobar Islands, where coseismic slips were large. However we obtained a rather small afterslip on the southernmost segment, which is resolved by the displacement at SAMP. Since we assume wider segments than the coseismic fault model, this suggests that afterslip may have occurred on the deep extension of the coseismic source region. Or there are spatial variations in slips that cannot be resolved by the present dataset. Several groups already started continuous observations in the Andaman-Nicobar Islands, Burma, and Sumatra etc. We expect that these observations give us invaluable information to resolve the afterslip distribution since they are much closer to the source fault.

The Andaman Sea is an active back-arc basin and may be opening. There are a couple of volcanic islands. Therefore there may be large heterogeneities in the crust and mantle beneath the Andaman Sea. We did not introduce viscoelastic response, since the time constant of the postseismic deformation at PHKT appears too short. There might be a highly viscous material beneath the Andaman Sea that is related to the back-arc opening. How large this heterogeneous structure affects the postseismic deformation is an interesting topic and we must incorporate numerical modeling that can deal with heterogeneous structures of the back-arc in the future.

\section{Conclusion}

We analyzed continuous GPS data in Asia and Australia before and after the December 26, 2004, Sumatra-Andaman earthquake and March 28, 2005 Nias earthquake, and obtained co- and postseismic deformations from these events. The following conclusions are derived from the analysis:

(1) Coseismic displacements from the December mainshock were observed about $3000 \mathrm{~km}$ away from the epicenter. GPS sites in Thailand and northern Sumatra gave displacements of $261 \mathrm{~mm}$ at Phuket and $138 \mathrm{~mm}$ at Sampari toward the epicenter.

(2) These observations suggest that larger slip than $13 \mathrm{~m}$ occurred beneath the Nicobar Islands. Resultant magnitude is estimated Mw 9.12.

(3) Large postseismic displacements are observed at Phuket and Sampari during the first month after the mainshock, but the ratio of displacements of Phuket to Sampari is different between coseismic and postseismic motions. 
This fact suggests that the spatial distribution of afterslip is different from the coseismic slip distribution.

(4) Temporal variation in postseismic displacements can be explained by logarithmic function derived from rate-state dependent friction law. Its characteristic time may be as short as a day.

(5) The area where coseismic displacement from the Nias earthquake of March 28, 2005 is detected is much smaller than that from the December mainshock. These displacements suggest about $3.6 \mathrm{~m}$ slip on a shallow dipping thrust fault.

(6) In total, seismic moment up to $3.83 \times 10^{22} \mathrm{Nm}$ may have been released by afterslip for about five months, which is equivalent to Mw 8.99, including the afterslip for the Nias earthquake.

Acknowledgments. We thank SOPAC and the Geographical Survey Institute for their service of archiving of GPS data. We must thank Peiming Wu from JAMSTEC who originally established the Thai sites. We also thank Roland Bürgmann, Kazuro Hirahara, Kazutoshi Sato for their helpful comments. We also appreciate Minoru Kasahara and an anonymous reviewer for the improvement of paper. We used the Generic Mapping Tools ver. 3.3.4 (Wessel and Smith, 1998) for the preparation of illustrations.

\section{References}

Ammon, C. J., C. Ji, H.-K. Thio, D. Robinson, S. Ni, V. Hjorleifsdottir, H. Kanamori, T. Lay, S. Das, D. Helmberger, G. Ichinose, J. Polet, and D. Wald, Rupture process of the 2004 Sumatra-Andaman earthquake, Science, 308, 1133-1139, 2005.

Banerjee, P. F. F. Pollitz, and R. Bürgmann, The size and duration of the Sumatra-Andaman earthquake from far-field static offsets, Sciencexpress, /www.sciencexpress.org/19 May 2005/Page 1/10.1126/science.1113746, 2005.

Bilham, R., A flying start, then a slow slip, Science, 308, 1126-1127, 2005.

Bock, Y., L. Prawirodirdjo, J. F. Genrich, C. W. Stevens, R. McCaffrey, C. Subarya, S. S. O. Puntodewo, and E. Calias, Crustal motion in Indonesia from global positioning system measurements, J. Geophys. Res., 108(B8), 2367, doi:10.1029/2001JB000324, 2003.

Earnest, A. and C. P. Rajendran, The deformation characteristics along the Andaman-Nicobar arc associated with the Dec. 26, 2004 megathrust earthquake: insights from GPS data, AOGS2005, 58-SE-A0286, 2005.

Heki, K., H. Tsuji, and S. Miyazaki, Silent fault slip following an interplate thrust earthquake at the Japan trench, Nature, 386, 595-598, 1997.

Hugentobler, U., R. Dach, and P. Fridez, Bernese GPS Software Version 5.0, AIUB, University of Bern, 388 pp., 2005.

Ikeda, Y., S. Kayane, T. Echigo, M. Shishikura, and M. Kamataki, Crustal deformations in Andaman Islands associated with the SumatraAndaman earthquake and paleoseismological evidence, Presented at the 164th Meeting of the Coordinating Committee for Earthquake Prediction, http://cais.gsi.go.jp/YOCHIREN/JIS/164/image164/013.pdf, 2005 (in Japanese).

Ishihara, Y. and N. Suda, Source image of 2004 Sumatra mega quake by earth's free oscillation analysis, Program and Abstracts of the 2005 Joint Meeting of the Earth and Planetary Sciences of Japan, J113-06, 2005.

Larsen, C.,F., K. A. Echelmeyer, J. T. Freymueller, and R. J. Motyka, Tide gauge records of uplift along the northern Pacific-North American plate boundary, 1937 to 2001, J. Geophys. Res., 108(B4), 2216, doi:10.1029/2001JB001685, 2003.

Lay, T., H. Kanamori, C. J. Ammon, M. Nettles, S. N. Ward, R. C. Aster, S. L. Beck, S. L. Bilek, M. R. Brudzinski, R. Butler, H. R. DeShon, G. Ekstrom, K. Satake, and S. Sipkin, The great Sumatra-Andaman earthquake of 26 December 2004, Science, 308, 1127-1133, 2005.

Marone, C., C. H. Scholz, and R. Bilham, On the mechanics of earthquake afterslip, J. Geophys. Res., 96, 8441-8452, 1991.

Miura, S., S. Yui, N. Uchida, A. Hasegawa, and Y. Yagi, Spatiotemporal Evolution of Postseimic Slip Following the 2003 Tokachi- oki Earthquake (M8.0) Estimated by GPS and Repeating Earthquakes, AOGS2005, 58-SE-A1378, 2005.

Miyazaki, S., P. Segall, J. Fukuda, and T. Kato, Space-time distribution of afterslip following the 2003 Tokachi-oki earthquake: implications for variations in fault zone frictional properties, Geophys. Res. Lett., 31, L06623, doi:10.1029/2003GL019140, 2004.

Murakami, M., Slow slip preceding M7 earthquake doublet in 2004 offshore eastern Hokkaido Japan along the Kuril trench, Program and Abstracts of the 2005 Joint Meeting of the Earth and Planetary Sciences of Japan, S088-004, 2005.

NEIC/USGS, http://neic.usgs.gov/neis/epic/epic.html, 2005.

Okada, Y., Surface deformation due to shear and tensile faults in a halfspace, Bull. Seismol. Soc. Amer., 75, 1135-1154, 1985.

Park, J., T-R. A. Song, J. Tromp, E. Okal, S. Stein, G. Roult, E. Clevede, G. Laske, H. Kanamori, P. Davis, J. Berger, C. Braitenberg, M. Van Camp, Lei, H. Sun, H. Xu, and S. Rosat, Earth's free oscillations excited by the 26 Decmenber 2004 Sumatra-Andaman earthquake, Science, 308, 1139-1144, 2005.

Rajendran, C. P., A. Earnest, K. Rajendran, R. Bilham, and J. T. Freymueller, A slow $\mathrm{Mw} \geq 8.7$ earthquake embedded in the Andaman segment of the great 2004 Sumatra rupture, Nature, 2005 (submitted).

Shishikura, M. and S. Tsuchida, Crustal movement of the Andaman Islands during the 2004 Sumatra earthquake, analyzed from ASTER data, Program and Abstracts of the 2005 Joint Meeting of the Earth and Planetary Sciences of Japan, J113p-011, 2005.

Stein, S. and E. Okal, Speed and size of the Sumatra earthquake, Nature, 434, 581-582, 2005.

Suito, H., M. Tobita, T. Imakiire, and M. Kaidzu, Fault model of 2004 Off Sumatra earthquake, Indonesia based on satellite images, Program and Abstracts of the 2005 Joint Meeting of the Earth and Planetary Sciences of Japan, J113-010, 2005.

Tabei, T. and W. L. Amin, Common-mode errors in the GPS coordinates time series-application of spatial filtering technique, J. Geod. Soc. Jpn., 48, 229-241, 2002.

Tobita, M., M. Kaidzu, M. Murakami, M. Tsuzawa, T. Imakiire, H. Yarai, H. Suito, Y. Fukuzaki, M. Kato, S. Fujiwara, A. Itabashi, and H. Nakai, Coastline change and tsunami inundation area of northern Sumatra Island inferred from satellite synthetic aperture radar images, Program and Abstracts of the 2005 Joint Meeting of the Earth and Planetary Sciences of Japan, J113-09, 2005.

Vigny, C., W. J. F. Simons, S. Abu, R. Bamphenyu, C. Satirpod, M. Chhosakul, C. Subarya, K. Omar, H. Z. Abindin, A. Socquet, and B. A. C. Ambrosius, Insight into the 2004 Sumatra-Andaman earthquake from GPS measurements in southeast Asia, Nature, 436, 201206, doi:10.1038/nature03937, 2005.

Wang, K., J. He, and H. Dragert Postseismic deformation of long-rupture $(\sim 900 \mathrm{~km})$ great subduction earthquakes and mantle viscosity, Seismol. Res. Lett., 73, 235, 2002.

Wdowinski, S., Y. Bock, J. Zhang, P. Fang., and J. Genrich, Southern California permanent GPS geodetic array: spatial filtering of daily positions for estimating coseismic and postseismic displacements induced by the 1992 Landers earthquake, J. Geophys. Res., 102, 18057-18070, 1997.

Wessel, P. and W. H. F. Smith, New, improved version of Generic Mapping Tools released, EOS Trans. Amre. Geophys. U., 79(47), 579, 1998.

Wu, C. and K. Koketsu, Rupture process of the $2004 \mathrm{Mw} 9.0$ off the west coast of northern Sumatra earthquake, Program and Abstracts of the 2005 Joint Meeting of the Earth and Planetary Sciences of Japan, J11304, 2005.

Yagi, Y., Preliminary results of rupture process for 2004 off coast of northern Sumatra giant earthqauke (ver. 1), http://iisee.kenken.go.jp/staff/ yagi/eq/Sumatra2004/Sumatra2004.html, 2005.

Yagi, Y., M. Kikuchi, and T. Sagiya, Co-seismic slip, post-seismic slip, and aftershocks associated with two large earthquakes in 1996 Hyuga-nada, Japan, Earth Planets Space, 53, 793-803, 2001.

Yamanaka, Y., Source process of 2004 Sumatra earthquake, Program and Abstracts of the 2005 Joint Meeting of the Earth and Planetary Sciences of Japan, J113-02, 2005.

M. Hashimoto (e-mail: hasimoto@rcep.dpri.kyoto-u.ac.jp), N. Choosakul, M. Hashizume, S. Takemoto, H. Takiguchi, Y. Fukuda, and K. Fujimori 